\begin{tabular}{|c|c|}
\hline Title & $\begin{array}{l}\text { Energy conservation using new structured-core and transparent vacuum insulation panels: Numerical simulation with } \\
\text { experimental validation }\end{array}$ \\
\hline Author(s) & Katsura, Takao; Radwan, A li; Y ang, Zhang; Nakamura, Makoto; Nagano, Katsunori \\
\hline Citation & $\begin{array}{l}\text { Solar energy, 193, 885-905 } \\
\text { https://doi.org/10.1016/.solener.2019.09.083 }\end{array}$ \\
\hline Issue Date & 2019-11-15 \\
\hline Doc URL & http:/hdl .handle.net/2115/83280 \\
\hline Rights & $\begin{array}{l}\text { ( ) <2019>. This manuscript version is made available under the CC-BY-NC-ND } 4.0 \text { license } \\
\text { http://creativecommons.org/icenses/by-nc-nd/4.0/ }\end{array}$ \\
\hline Rights(URL) & http://creativecommons.org/icenses/by-nc-nd/4.0/ \\
\hline Type & article (author version) \\
\hline File Information & Revised manuscript2.pdf \\
\hline
\end{tabular}

Instructions for use 


\title{
Energy Conservation using New Structured-Core and Transparent Vacuum Insulation Panels: Numerical Simulation with Experimental Validation
}

\author{
Takao Katsura*1, Ali Radwan ${ }^{1,2}$, Zhang Yang ${ }^{3}$, Makoto Nakamura ${ }^{1}$, Katsunori Nagano ${ }^{1}$ \\ ${ }^{1}$ Division of Human Environmental Systems, Faculty of Engineering, Hokkaido University, \\ N13-W8, Kita-ku, Sapporo 060-8628, Japan \\ ${ }^{2}$ Department of Mechanical Power Engineering, Mansoura University, El-Mansoura 35516, Egypt \\ ${ }^{3}$ Country Garden, Beijiao Town, Shunde District, Foshan, Guangdong 528312, China \\ * Corresponding author: Tel: +81-11-706-6284, e-mail: katsura@eng.hokudai.ac.jp
}

\section{Abstract}

The rate of heat gain or heat loss from the windows of existing buildings represents a large portion of building energy consumption in harsh hot or cold regions, respectively. Therefore, several thermal insulation technologies have been applied in new buildings. However, these technologies are difficult to implement in existing buildings. Therefore, this study proposes a new, low-cost insulation method using slim, transparent panels with structured cores, for the windows of existing buildings. To do this, five new distinct designs of vacuum insulation panels (VIPs) are proposed to retrofit insulation for the windows of existing buildings. The VIPs comprise a hollow-frame structured-core material encapsulated in a transparent multi-layered polymeric envelope. The effective thermal conductivity of VIPs with different spacers, namely, peek, modified peek, mesh, silica aerogel, and frame, are evaluated at different pressure levels. The spacers are 3D-printed and experimentally-examined. A 3D thermal model is developed and validated using the experimental results of the present work and results from the literature. First, the influences of spacer structure and vacuum pressure on the centre-of-panel thermal conductivity, light transparency, and VIP production costs are evaluated. Second, three different trial manufacturing methods for these VIPs are proposed and compared. Finally, the annual building heat gain and heat loss in two different harsh hot and cold regions, respectively, in Japan are estimated while applying these new proposed VIP designs to the existing windows. The results indicate that VIPs with frame and mesh spacers accomplish better insulation performance, with a centre-of-panel thermal conductivity of $7 \times 10^{-3} \mathrm{~W} / \mathrm{m} . \mathrm{K}$ at a pressure of $1 \mathrm{~Pa}$. Further, the VIP with the peek spacer accomplishes the highest light transparency (0.88). Furthermore, using a frame-type VIP with a total thickness of $3 \mathrm{~mm}$ attached to an existing window as a curtain decreases the space heat loss by approximately $69.5 \%$, whereas the light transparency decreases to $75 \%$. In that regard, using a frame-type VIP attached to 3 mm-glass windows decreases window insulation costs by $72 \%$ compared with vacuum glazing thermal insulation.

Keywords: Vacuum insulation panel; structured-core and transparent; retrofitting insulation; surface-tosurface radiation; 3D modelling

\section{Highlights}

- Five distinct structured-core and transparent vacuum insulation panels are analysed.

- A 3D model is used to predict the insulation ability.

- VIPs with mesh and frame spacers achieve better insulation performance. 
- The proposed VIPs are cost-effective when compared with silica aerogels and vacuum glazing.

- VIPs with pillar spacers provide the highest light transparency.

\section{Introduction}

Environmental problems and energy exhaustion have become major global issues. The annual energy consumption is increasing every year, and the amount of environmental pollution is accelerating. In this regard, many energy-saving technologies for building applications have been installed in new buildings. Meanwhile, old buildings are often protected for their aesthetical and historical contributions to society. However, the aforementioned energy-saving technologies are rarely installed in such existing buildings. The insulation ability of the existing buildings is poor; therefore, it is vital to improving their insulation performance. Vacuum insulation panels (VIPs) are panels characterised by very low thermal conductivity as compared to traditional insulating materials (Fricke et al., 2008). For this reason, they represent a promising solution for improving the thermal behaviour of buildings, especially in the case of energy retrofitting (where higher performance and smaller thicknesses are desirable) (Boafo et al., 2019). Further, it is essential to decrease the summer heat gain or winter heat loss in the windows of the existing buildings. At the same time, keeping the transparency of the window as high as possible is essential for decreasing the lighting energy consumption during the daytime (Yang et al., 2017).

The research on VIPs has been applied in some fields to improve insulation performance. For example, in some buildings, it can attain 5 times higher insulation values than traditional building insulating materials (Fantucci et al., 2019). It has also been widely applied in vacuum cups and refrigerators (Thiessen et al., 2018). A vacuum pipe has been applied in evacuated-tube solar collectors (Farid Arya et al., 2018). The study of vacuum insulation technology, as applied to buildings, began in the 1990s. The VIP apparent thermal conductivity ranges from 10 to $20 \%$ of that of conventional insulation materials such as glass wool, expanded polystyrene, and polyurethane foam (Choi et al., 2016). The VIP consists of filler material and a gas barrier envelope. The filler material has a porous structure with an open cell. This filler facilitates the inner air evacuation. Different types of filler materials have been examined and tested in recent years (Choi et al., 2016; Lee and Song, 2019; Liang et al., 2017; Paneri et al., 2019). For instance, (Kim et al., 2012b) used phenolic foam as a filler material for a VIP. They concluded that the effective total thermal conductivity of the VIP was approximately $5 \times 10^{-3} \mathrm{~W} / \mathrm{m}$.K at a vacuum of $0.02 \mathrm{~Pa}$, with $5 \%$ uncertainty in the measurement. Moreover, the same research group experimentally evaluated the insulation ability of a VIP with glass wool with a minimum centre-of-panel thermal conductivity of $1.2 \times 10^{-3} \mathrm{~W} / \mathrm{m} . \mathrm{K}$, and that of opacified fumed silica with a minimum centre-of-panel thermal conductivity of $2.5 \times 10^{-3} \mathrm{~W} / \mathrm{m} . \mathrm{K}$, as fillers at different pressing loads and pressure levels in (Kim and Song, 2013). Owing to the permeable open structure of these types of fillers, they concluded that the VIP volume changes by the evacuation. In addition, by applying the pressing load, the filler solid conduction increases, but the radiative thermal conductivity decreases. Glass fibre is also used as the core material in a VIP for high-temperature applications in (Araki et al., 2009). (Choi et al., 2016) proposed a new VIP consisting of two stainless steel plates, with pillar support to sustain the atmospheric pressure. In their work, heat transfer and mechanical stability were analysed together in the design stage. Then, to further decrease the conduction heat transfer through the 
pillar, a multi-pass support (MPS) pillar with a cup-shaped holder was suggested and investigated. They concluded that they attained a VIP with a very low effective thermal conductivity, i.e. approximately $1.18 \times 10^{-3} \mathrm{~W} / \mathrm{m}$.K. In the recent investigations, the manufactured VIPs are proposed for insulating walls in a building. These structures of VIPs are the most common, and provide an opaque view. Therefore, the light transparency through the VIP was not a main concern. These structures consist of a metallized film barrier, i.e. an "aluminium envelope placed inside the structure of a building wall".

Silica powder has been applied for the trial manufacture of VIPs. A silica aerogel with a thermal conductivity of $2 \times 10^{-2} \mathrm{~W} / \mathrm{m} . \mathrm{K}$ is usually used to make transparent VIPs (Buratti et al., 2017). It has been found that using such material in smart windows decreases the U-values by $63 \%$ as compared to conventional glass windows. In addition, a significant reduction in the light transmittance (by approximately 30\%) has been measured (Buratti et al., 2017). Moreover, the industrial production cost of a VIP using silica aerogel remains very high. Hence, there is a need to search for another economically competitive material.

Several trials for different filler materials have recently been investigated. Polyethylene terephthalate (PET) film is applied via aluminium vapour deposition as a core material for analysis, and is considered the core material of the metallic multilayer and overlapping fibre (Kim et al., 2012a). An analysis of a heat transfer model for a nonporous silica vacuum insulation material was reported by (Bouquerel et al., 2012a). Recently, Paneri et al., 2019 published a comprehensive review paper regarding the materials used in transparent insulation panels. Based on this review, the authors concluded that an aerogel quasi-homogeneous geometrical structure is an effective insulation material, achieving a centre-ofpanel U-value of $0.25 \mathrm{~W} /\left(\mathrm{m}^{2} . \mathrm{K}\right)$ with a thickness of $70 \mathrm{~mm}$. However, the insulation cost of using silica aerogels remains a challenging problem. Kwon et al., 2009 proposed powder-type, foam-type, and fibretype fillers, and then described a heat transfer model of the core material with a staggered beam. They concluded that the fibre and staggered-beam thermal conductivities were lower than those of powder and foam, owing to the longer thermal path. Johansson et al., 2012, proposed a short-term in situ performance measurement of VIPs, and its accuracy is being verified. An outgassing problem from the VIP core material and envelope was investigated in (Kwon et al., 2011) and reviewed in (Bouquerel et al., 2012b; Fricke et al., 2008). The polymer fibre was also examined to analyse the reason for outgassing, as proposed by (Kwon et al., 2011). In addition, the gas invasion from the film is described as a mass transfer model inside of the film by (Bouquerel et al., 2012b).

Many numerical models and experimental methods have been used over the past several years to evaluate the apparent thermal conductivity of VIPs with different core materials. Some of these consider one-dimensional models (Baetens et al., 2010; Choi et al., 2016; Jung et al., 2014; Kwon et al., 2009), some used two-dimensional models (Jang et al., 2011; Kim et al., 2012a; Lorenzati et al., 2016; Spagnol et al., 2007), and a few other studies used 3D models (Fang et al., 2007; Johansson et al., 2012). Among these investigations, pillar-supported VIPs are the most commonly investigated (F. Arya et al., 2018; Choi et al., 
2016), and these VIPs were applied for the walls of buildings. Therefore, they were not transparent VIPs. Furthermore, the effects of changing the support structure are rarely addressed in the literature. In addition, in most of the modelling methods, each component of the VIP effective thermal conductivity is determined separately, and then the components are summed together. However, the coupling of the gas conduction, vacuum region radiation, and the support structure conduction is very limited (Spagnol et al., 2007). Therefore, the literature rarely discusses proposing different VIP core structures for transparent VIPs with low thermal conductivity and competitive prices, as compared to silica aerogel panels and traditional vacuum glazing insulations.

Based on the previous literature survey, this work aims to propose a new slim structured-core and transparent insulation method for windows of existing buildings, with a lower cost than vacuum glazing technology. Therefore, the originality of the present study is based on four main aspects. First, five distinct designs for VIP spacer structures to retrofit the existing windows are conceived, manufactured, and examined. The proposed VIPs are translucent and slim, and can be closely-fitted to the windows of existing buildings by direct attachment. Second, new experimental methods that simultaneously evacuate and measure the VIP thermal conductivity are used. Third, a 3D heat-transfer model is developed. This model simultaneously solves all mechanisms of heat transfer existing in the VIP, including spacer bridge conduction, vacuum gas conduction, and surface-to-surface radiation. This model allows us to evaluate the contributions of all of the existing heat transfer mechanisms, which is essential for evaluating the conditions at which each part could be the controlling parameter. Finally, annual estimations of building heat gain and loss in two different hot and cold regions in Japan are respectively analysed for the five proposed VIP designs. The types of VIPs investigated in this manuscript are very different from well-known conventional VIPs, which have a solid core material structure and opaque aluminium foil or a metallized film barrier envelope. The VIPs addressed in this manuscript have a hollow-frame structured-core material encapsulated in a transparent multi-layered polymeric envelope; neither material is commonly used.

\section{Physical problem}

As mentioned above, a metallized film barrier envelope is commonly used in VIPs with solid core materials for building insulations. This film is opaque, meaning that it cannot be applied to existing windows. The appearance of vacuum glazing has generally solved this issue. However, these film barrier envelopes have a relatively high cost and contribute less to retrofitting in buildings, owing to their single purpose and very heavy weight. Therefore, this paper proposes five new designs of VIPs to be attached to existing windows. A concept diagram of the proposed VIPs is shown in Fig. 1. The steps for the manufacturing of the VIP are shown on the left side. The manufacturing steps start with the preparation of the VIP core structure, low-emissivity (L-e) sheet, and transparent envelope. In this work, the heat sealing of the envelope is a four-sided seal type. In addition, the L-e film is coated on one face for a measured emissivity of 0.28 , whereas the other face has a larger emissivity of 0.77 . This type of L-e film is used because for the same area, the single-face-coated L-e film has a lower price as compared to the two-sided coated film. Therefore, it contributes to lowering the total cost of the VIP. In this work, the L-e side is directed to the vacuum space. This structure decreases the contribution of the radiation heat transfer, which 
is the dominant factor at very low-pressure levels (as will be discussed later). The core structure and the Le film are inserted in a transparent gas barrier envelope. The transparent envelope facilitates the applicability of these VIPs to existing windows where light transparency is indispensable. The full structure is evacuated and sealed in a vacuum sealing machine after reaching the vacuum design pressure. The real photos, schematic representation, and the field applications of the VIPs are depicted in Fig. 1 from the left to the right of the figure. The proposed VIPs could assist in enhancing the insulation ability of existing windows, with light transparency. In addition, the proposed VIPs can be considered as thermal-insulating transparent curtains.

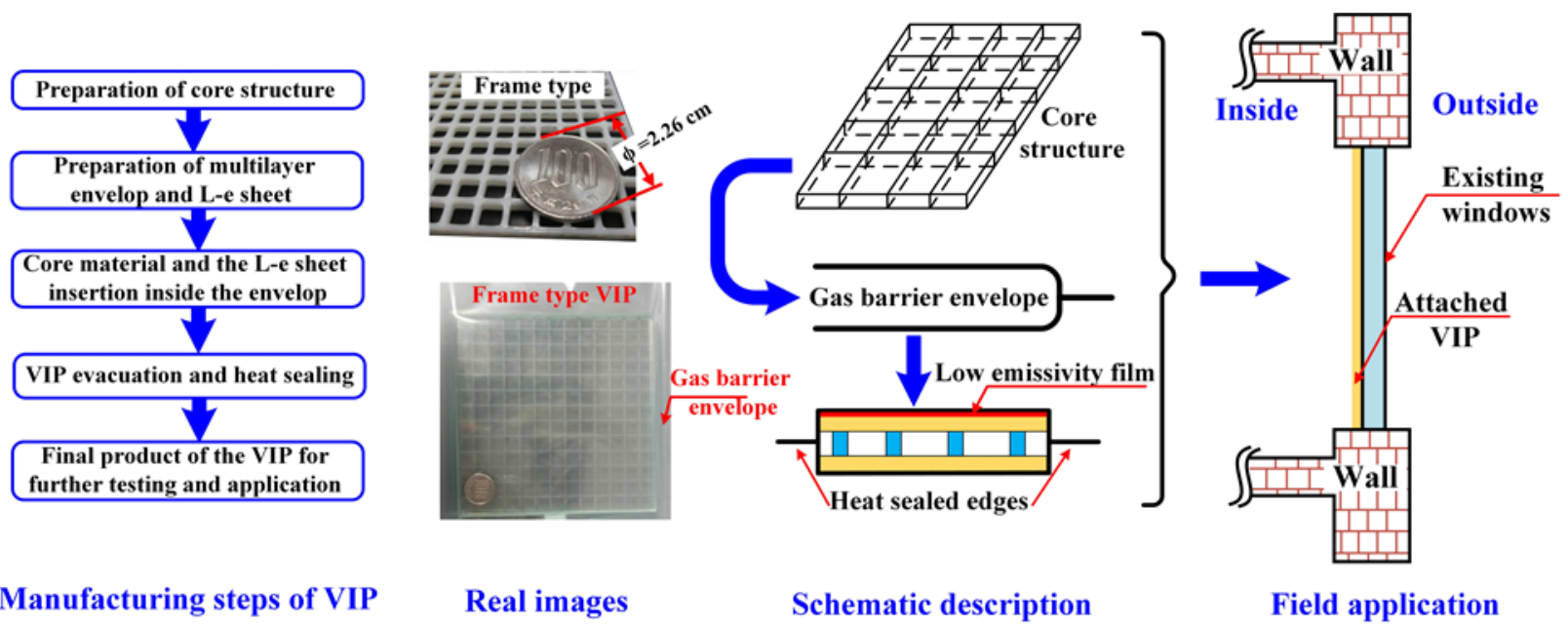

Fig. 1 Manufacturing steps, real images, schematic description, and the proposed real field application of the structured-core and transparent vacuum insulation panel (VIP) for existing windows.

The current VIPs are carefully designed for light transparency requirements. For instance, a transparent gas barrier film is applied as a covering envelope for the structured core. This envelope is favourable for sealing and transparency. The detailed structure and dimensions of the gas barrier envelope are depicted in Fig. 2.

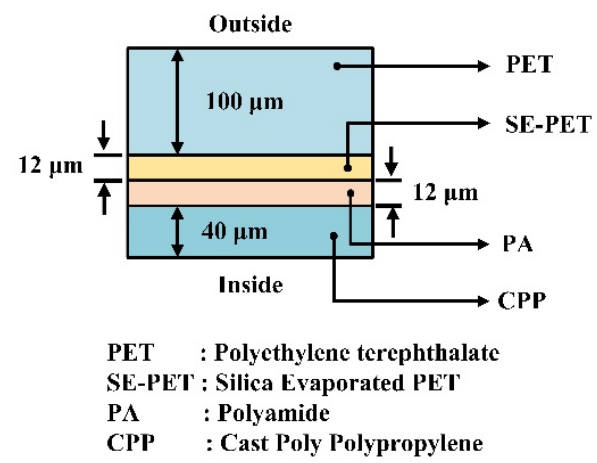

Oxygen transmission rate (OTR) $<0.1 \mathrm{cc} /\left(\mathrm{m}^{2}\right.$.atm.day) $\left(25^{\circ} \mathrm{C}, 80 \% \mathrm{RH}\right)$ Moisture transmission rate (MTR) $<0.1 \mathrm{~g} /\left(\mathrm{m}^{2}\right.$. .day) $\left(40{ }^{\circ} \mathrm{C}, 80 \% \mathrm{RII}\right)$ Puncture resistance (PR) and gas transmission rate (GTR) are unknown Heat seal strength $(\mathrm{HSS})=2 \mathrm{~kg} \mathrm{f} /($ width $15 \mathrm{~mm})$

Fig. 2 Detailed structure of the transparent gas barrier envelope used in the present work with properties essential for VIP life cycle analysis.

In this study, the insulation performance is implemented for five different designs of structured-core and transparent VIPs, as shown in Fig. 3. These VIP designs include a peek spacer, mesh spacer, frame spacer, modified peek spacer, and silica aerogel spacer. All of these VIPs are designed, 
manufactured, and experimentally-tested, except for the modified peek spacer. The modified peek spacer and another cylindrical pillar are proposed as extensions for the peek spacer. Therefore, the experiment will be conducted for the peek spacer and validated with a numerical model, and the same numerical model and solution methods will be applied for the modified peek spacers and cylindrical pillar. The modified peek spacer, peek spacer, and cylindrical pillar will be compared together to highlight methods for decreasing the conduction heat flux in pillar-supported VIPs.

Before discussing the design details of the structured-core and transparent VIPs used in this work, it is worth mentioning that at low pressures, the gas conduction is very small, and the effects of gas convection can be neglected (Choi et al., 2016; Fang et al., 2007; Memon et al., 2019a). The dominant parameters that can be controlled to decrease the effective thermal conductivity of a VIP in low-pressure conditions are the radiation heat transfer and the thermal bridges through the outside frame and inner core structure. Therefore, to enhance the VIP insulation performance, this work decreases the radiation by implementing the L-e film. In contrast, the heat conduction through the support structure is decreased by changing the core structure from a common solid core structure to hollow-designed core structures, as depicted in Fig. 3.

As shown in Fig. 3, a peek spacer is a modified design of a cylindrical pillar-supported VIP. A conventional pillar-supported VIP uses a continuous cylindrical cross-section pillar with a diameter of (D). This design is the most widespread in the literature, and is used for vacuum glazing technology (Fang et al., 2010). However, the peek design differs from the existing structures, as it decreases the diameter of the pillar to (d) while maintaining the pillar diameter head as (D). This decreases the space occupied by the pillar, and slightly enhances the light transparency. In addition, it is possible to attain a decrease in the pillar thermal bridge. To further utilise the same idea, a modified peek pillar-supported VIP is proposed. In this type of pillar-supported VIP, a semi-spherical head is used for the pillar. In such a case, the connection between the hot side and cold side can be reduced, and the thermal bridges through the pillars can be further decreased. In the pillar-supported VIPs in this work, i.e. peek and modified peek, an acrylic plate with $\delta=$ $1 \mathrm{~mm}$ is used to fix the pillars inside it. In addition, other two acrylic plates with $\delta$ of $1 \mathrm{~mm}$ each are used to keep the vacuum space at one plate, with a thickness of $\delta$ at each side. In these two cases, a vacuum space can be obtained, with a thickness of $\mathrm{H}_{\mathrm{v}}=1.5 \mathrm{~mm}$. Therefore, the total thickness of the pillar-supported VIPs (with the peek spacer or modified peek spacer) in this study is $4.5 \mathrm{~mm}$. The pillars are fabricated from polycarbonate with a thermal conductivity of $0.2 \mathrm{~W} / \mathrm{m} . \mathrm{K}$ (Choi et al., 2016). The detailed dimensions of the VIPs are provided in Table 1.

Table 1: Detailed dimensions of the current structured-core and transparent vacuum insulation panels (VIPs).

\begin{tabular}{cccc}
\hline Dimension & Value $(\mathrm{mm})$ & Dimension & Value $(\mathrm{mm})$ \\
\hline$\delta$ & 1 & $\mathrm{D}$ & 1.8 \\
$\mathrm{~W}_{\mathrm{p}}$ & 150 & $\mathrm{~L}_{\mathrm{p}}$ & 150 \\
$\mathrm{~d}$ & 1.2 & $\mathrm{H}_{\mathrm{v}}$ & 1.5 \\
$\delta_{\mathrm{s}}$ & 10 & $\mathrm{~L}_{\mathrm{s}}$ & 5 \\
\hline
\end{tabular}


To further decrease the thermal bridges through the spacer structure, a mesh-type spacer is proposed, as 215 shown in Fig. 3. The mesh-type spacer consists of an equal-squares mesh fabricated by the sewing of 216 circular polycarbonate rods, each with diameter $\delta=1 \mathrm{~mm}$. This approach decreases the connection area 217 between every two rods to just a point. Thus, the heat transfer by conduction can be lowered, owing to the 218 significant reduction in the connection area. In this case of the VIP, the total thickness of the panel is $2 \mathrm{~mm}$. 219 The main advantages of this design are an easier fabrication process and a slim appearance. As shown in 220 Fig. 3, the frame-type spacer uses two 3D printed frames that have a uniform thickness throughout and are spaced by rectangular pillar supports. In the top layer of the frame, the pillars are 3D-printed and compressed to the lower frame. The total thickness of this panel is approximately $3 \mathrm{~mm}$, and no acrylic plates are used to keep the vacuum space, as in the case of pillar-supported VIPs. Finally, as a reference case, a common transparent VIP uses silica aerogel spacers. Therefore, a silica aerogel spacer with dimensions of $L_{s}=2.5 \mathrm{~mm}$ and a thermal conductivity of $0.02 \mathrm{~W} / \mathrm{m} . \mathrm{K}$ is used between two acrylic plates with $1 \mathrm{~mm}$ thickness each. The space between the two consecutive spacers is designed based on a deflection analysis developed by the author in a previous work (Yang et al., 2017). Therefore the $\delta_{\mathrm{s}}$ used in this work is $10 \mathrm{~mm}$, to maintain the deflection between the two consecutive supports less than $0.5 \mathrm{~mm}$ (Yang et al., 2017). 
Case name

Plan view
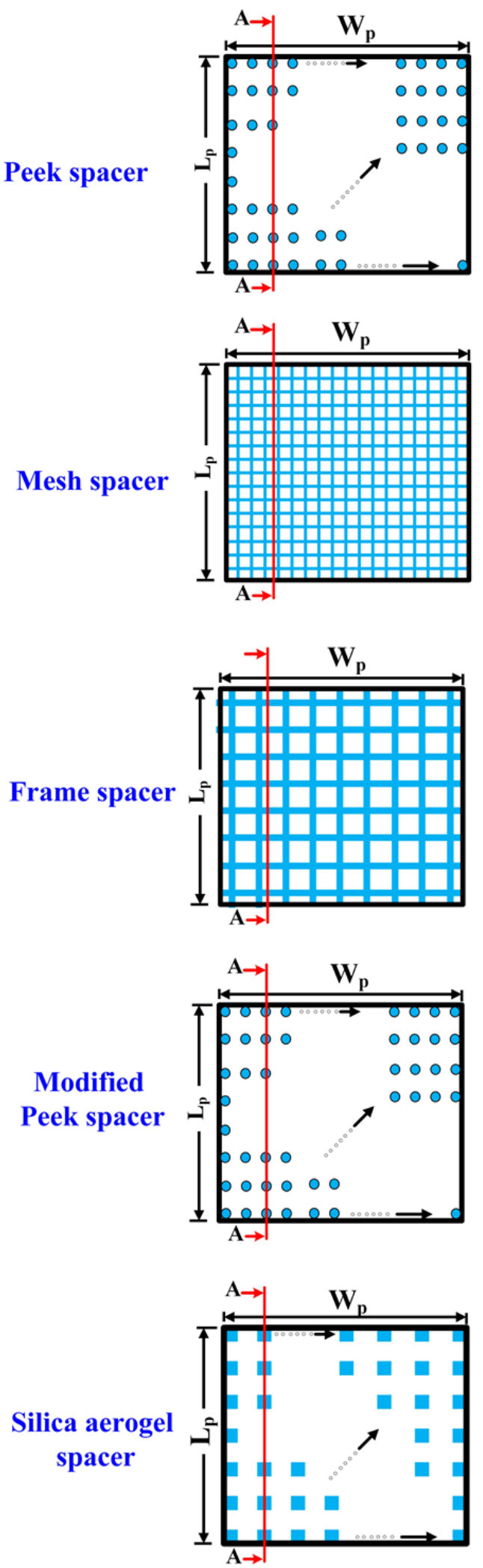

View at A-A

Spacer dimensions
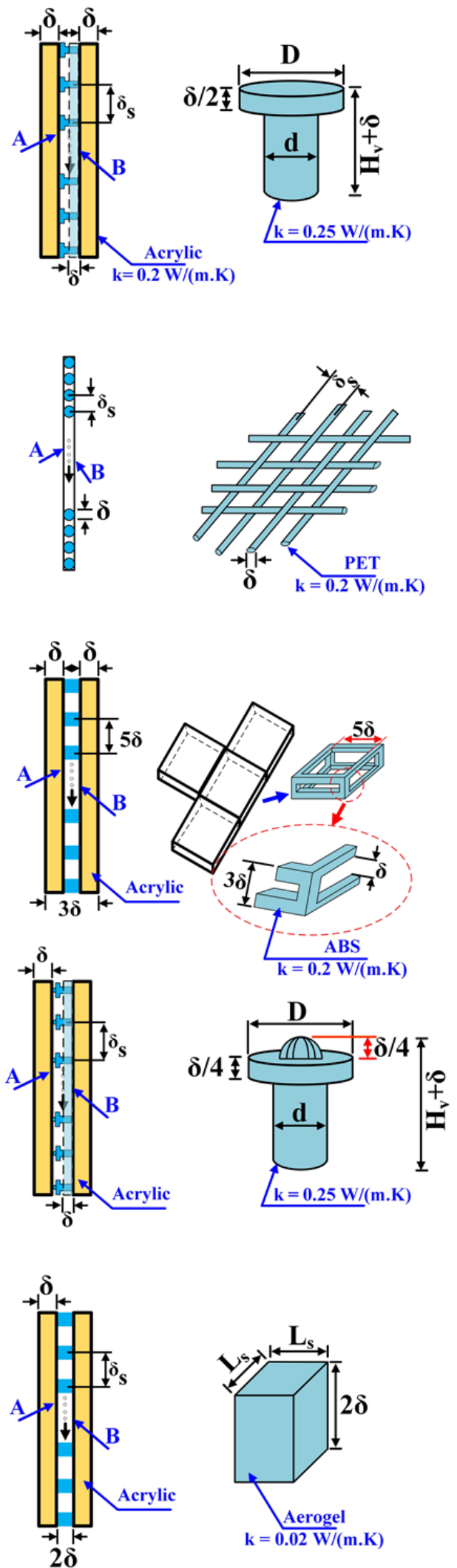

Fig. 3 Concept diagram of the proposed structured-core and transparent VIPs with different core structures of peek spacer, mesh spacer, frame spacer, modified peek spacer, and silica aerogel spacers. 


\section{Experimental setup}

Four experimental setups are established to produce and measure the relevant characteristics of the current structured-core and transparent VIPs. The first setup is used to measure the emissivity of the L-e coated film. The second setup is used for the production process of low-pressure VIPs, with simultaneous measurement of the panel thermal conductivity at different pressure levels. In the third experimental setup, four-trial production methods for the VIPs are compared. In the last setup, a light transparency test is conducted to evaluate the transparency of the proposed VIPs. All of the experimental setups are discussed in detail in the following sections.

\subsection{Measurements of the emissivity of the L-e film}

The cost of a single-face coated L-e film represents approximately $50 \%$ of the total cost of the VIP. This cost increases to approximately $65 \%$ in the case of using a double-face coated L-e film. Therefore, to keep the proposed VIPs cost-effective for smart windows, a single-face coated L-e film is used. In this type of L-e film, the emissivity of each face is different. In addition, it is essential to keep the L-e side oriented to the inside of the vacuum space. In view of this, an evaluation of the real emissivity value of the L-e film is essential for developing a thermal model. Consequently, an experiment is conducted to define the coated surface, and to measure the real emissivity of each side. The measurement is performed using an emissometer with a scaling digital voltmeter (Model AE1 RD1). This setup consists of a detector, finned heat sink, scaling digital voltmeter, and device power supply. A real photo of the setup and the schematic layout are depicted in Figs. 4-a and b, respectively. The detector portion is electrically heated. A finned heat sink is provided with the device to keep both a calibration standard and the L-e film at the same temperature. The scaling digital voltmeter is used to monitor the measured sample emissivity. Before conducting each experiment, a calibration is performed by using the standard emissive sample provided with the device. The measurement begins with the calibration step. In this step, a calibration standard sample with a known emissivity of 0.88 is inserted between the detector and the heat sink. Then, a variable resistance is manually changed, until reaching the exact emissivity of the standard sample. After that, the standard calibrated sample is replaced with the L-e film. After reaching a steady state condition, the emissivity of the film side facing the detector can be measured. The same step is repeated for the other face of the film. In the current experiments, the emissivities of the two sides of the film are approximately 0.28 and 0.77 , respectively.

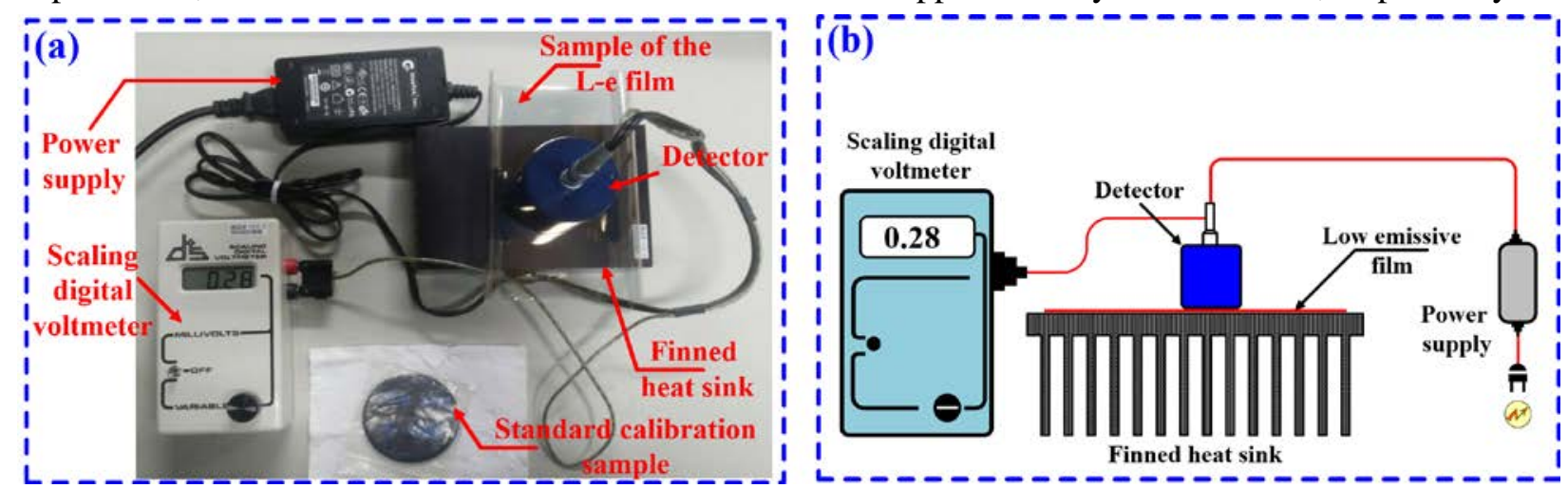

Fig. 4 Experimental setup for the measurement of the film real emissivity; (a) real photograph and (b) schematic representation of the setup. 


\subsection{Development of the vacuum insulation panel (VIP) and measurement of the effective thermal conductivity}

Initially, two vacuum methods are used to produce the VIP. The first system uses a lab-scale vacuum sealing machine. In this machine, the pressure level can be controlled either automatically or manually. After reaching the desired pressure, sealing is automatically performed. Then, the sample can be taken from the vacuum chamber and used for further testing. This sealing machine consists of buster and rotary vacuum pumps connected in series. A sealing width of $9 \mathrm{~mm}$ can be achieved using such a machine. This large sealing width prevents the penetration of atmospheric pressure, as compared with conventional sealing methods with a sealing width of $4 \mathrm{~mm}$. However, the controlled pressure is the machine chamber pressure. Moreover, the chamber pressure is slightly different than the real pressure inside the VIP after the sealing. This is because after the sealing is made, the pressure inside the VIP starts to increase, owing to outgassing from the core material, and other factors as explained in (Kwon et al., 2011) and discussed in the results section.

In contrast, the new measurement method applied herein is used to keep the pressure inside the VIP nearly constant during the thermal conductivity measurement. This method simultaneously accomplishes evacuation and thermal conductivity measurement. In this system, another small-scale vacuum system is connected to the heat flow meter (HFM) apparatus. Three sides of the envelope are thermally sealed after inserting the VIP core structure and the L-e film. The sealing is performed using the vacuum sealing machine, with a sealing width of $9 \mathrm{~mm}$. Then, the last side of the envelope is kept open to be connected to a small-scale vacuum system using a hose/pipe, as shown in Fig. 5. The schematic apparatus and a real photo of the simultaneous evacuation thermal conductivity measurements are depicted in Figs. 5-a and b, respectively. The vacuum system in this experiment consists of a reciprocating vacuum pump and a drytype turbomolecular vacuum pump connected in series. For the measurement of pressure, a Pirani pressure gauge with a pressure display unit is connected at the inlet of the VIP. The VIP with the pressure measurement device can be isolated from the evacuation system using a valve. First, the reciprocating pump is used to lower the pressure inside the VIP to approximately $20 \mathrm{~Pa}$. After that, the turbomolecular pump is used to further decrease the pressure to the desired value. A dry-type or oil-free turbomolecular pump is favourable for such applications, as recommended by (Memon et al., 2019b). The pressure sensor is located as closely as possible to the VIP, to measure the approximate pressure inside the VIP. After reaching the desired vacuum level, the VIP sample is inserted into the HFM apparatus. In this apparatus, the temperature of the hot and cold sides of the VIP can be controlled by using the controlling unit, either from the controller interface, or via system software on a PC. The steady-state hot- and cold-side temperatures of the HFM are kept constant at $35.5^{\circ} \mathrm{C}$ and $10.5^{\circ} \mathrm{C}$, respectively, during all of the tests. The instrument also has a facility for measuring the total thickness of the sample. The HFM has two heat flux sensors for accurate measurements of the heat fluxes, one on each side of the VIP. After reaching the steady-state criteria with a change in the measured heat fluxes of approximately $2 \%$, the measured sample thermal conductivity, thickness, walls temperature, sample mean temperature, and heat flux values are automatically displayed on the meter interface, and are transmitted to the meter software on the PC and recorded. 
The effective thermal conductivity of the VIP is measured based on a Fourier equation of onedimensional heat conduction, as given in the manufacturing datasheet of the HFM apparatus:

$$
\lambda_{e f f, \exp }=\left(\frac{q_{h}+q_{c}}{2}\right) \times \frac{L_{v}}{\Delta T}
$$

Here, $\lambda_{\text {effexp }}, q_{h}, q_{c}, l_{v}$, and $\Delta T$ are the effective measured thermal conductivity of the VIP (in W/m.K), 310 the measured heat flux on the hot and cold sides of the sample using the heat flux sensors ( in $\mathrm{W} / \mathrm{m}^{2}$ ), the 311 measured VIP thickness (in $\mathrm{m}$ ), and the temperature difference on the sides of the sample (in ${ }^{\circ} \mathrm{C}$ ), 312 respectively. In this work, the thermal conductivity is measured for all of the VIPs, except for the modified 313 peek spacers (which are numerically investigated, and are not manufactured). The technical specifications 314 of the measuring tools and their accuracies are depicted in Table 2.

315 Table 2 Technical specifications of the instruments used in the thermal conductivity measurements.

\begin{tabular}{cll}
\hline Instrument & \multicolumn{2}{c}{ Technical specifications } \\
\hline & Model No & $\mathrm{HC}-074$ \\
Heat flow & Accuracy & $\leq 1 \%$ \\
meter (HFM) & Repeatability & $0.2 \%$ \\
apparatus & Hot plate temperature range & $5{ }^{\circ} \mathrm{C}$ to $75^{\circ} \mathrm{C}$ \\
& Cold plate temperature range & $-20^{\circ} \mathrm{C}$ to $50^{\circ} \mathrm{C}$ \\
& Thermal conductivity range & 0.005 to $0.8 \mathrm{~W} / \mathrm{m} . \mathrm{K}$ \\
\hline \multirow{3}{*}{ Pirani gauge } & Model No & ST2-1 \\
& Pressure range & $10^{-5}$ to $10^{-3} \mathrm{~Pa}$ \\
& Accuracy & $\pm 10 \%$ when $10^{-5} \leq P<3 \mathrm{~Pa}$ \\
& & $\pm 15 \%$ when $3 \leq P \leq 10 \mathrm{~Pa}$ \\
\hline
\end{tabular}



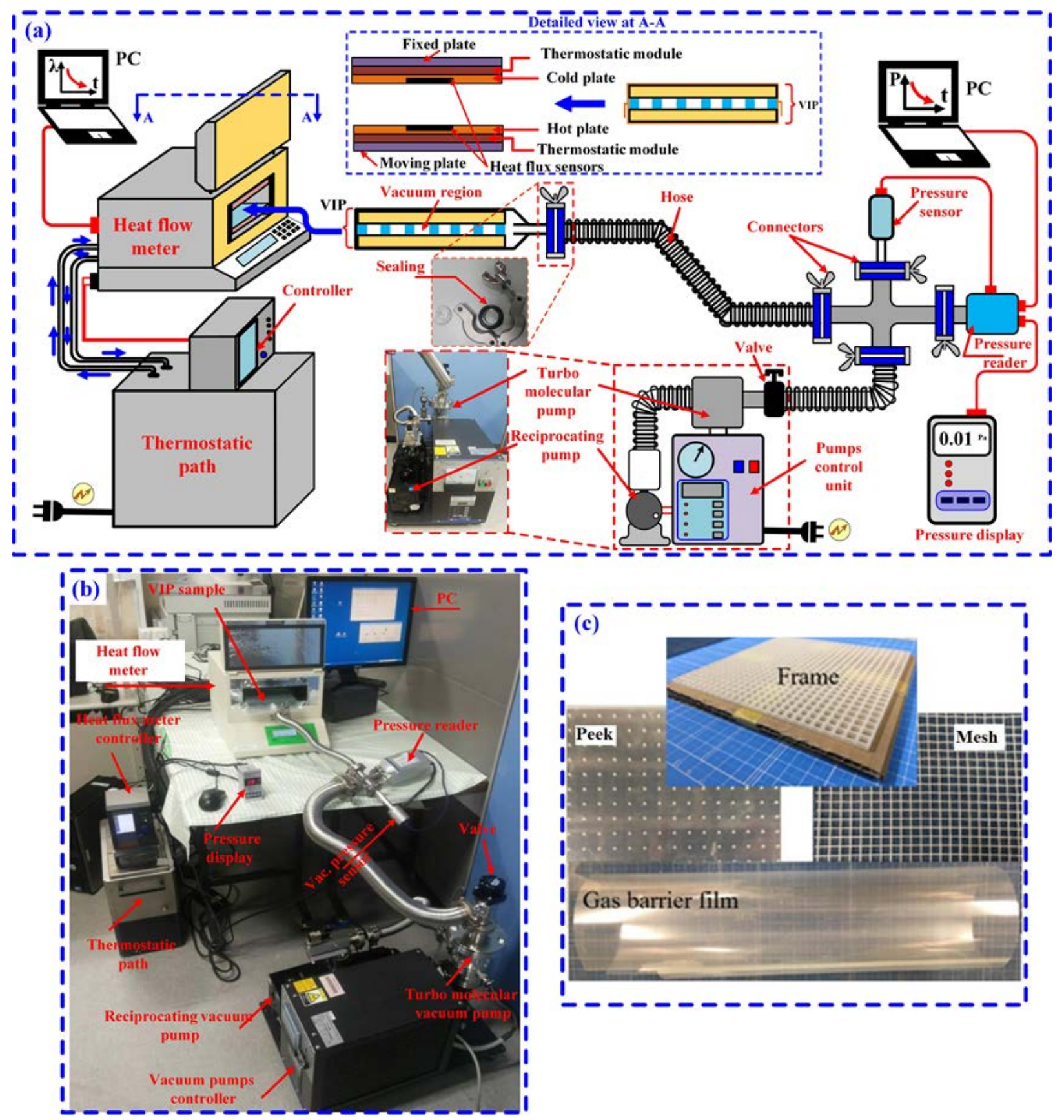

Fig. 5 Detailed experimental setup used for the evaluation of the centre-of-panel thermal conductivity

(a) schematic representation of the setup, (b) real photo of the experimental apparatus, and (c) real photo of peek, frame, and mesh VIPs with the gas barrier film.

\subsection{Experimental methods for the trial production of the VIP}

Before conducting the experiment presented in Section 3.2, a lab-scale vacuum sealing machine, as seen in Fig. 6, is used for the evacuation and sealing. In this setup, the sample inside the vacuum chamber is connected to the Pirani gauge to measure the pressure inside the VIP. However, it was found that after the sealing was performed, the inside pressure of the VIP increased from $0.24 \mathrm{~Pa}$ to $1.15 \mathrm{~Pa}$ in 10 minutes for the frame-type VIP. This is attributed to the outgassing from the core material and the sealed edges of the envelope (Kwon et al., 2011). In that regard, to measure the VIP thermal conductivity, it is essential to 
perform the evacuation and the sealing, and then to subsequently transfer the sample to the measuring HFM apparatus. In this case, with the outgassing from the core structure, the estimation of the exact inner pressure of the VIP is very difficult.
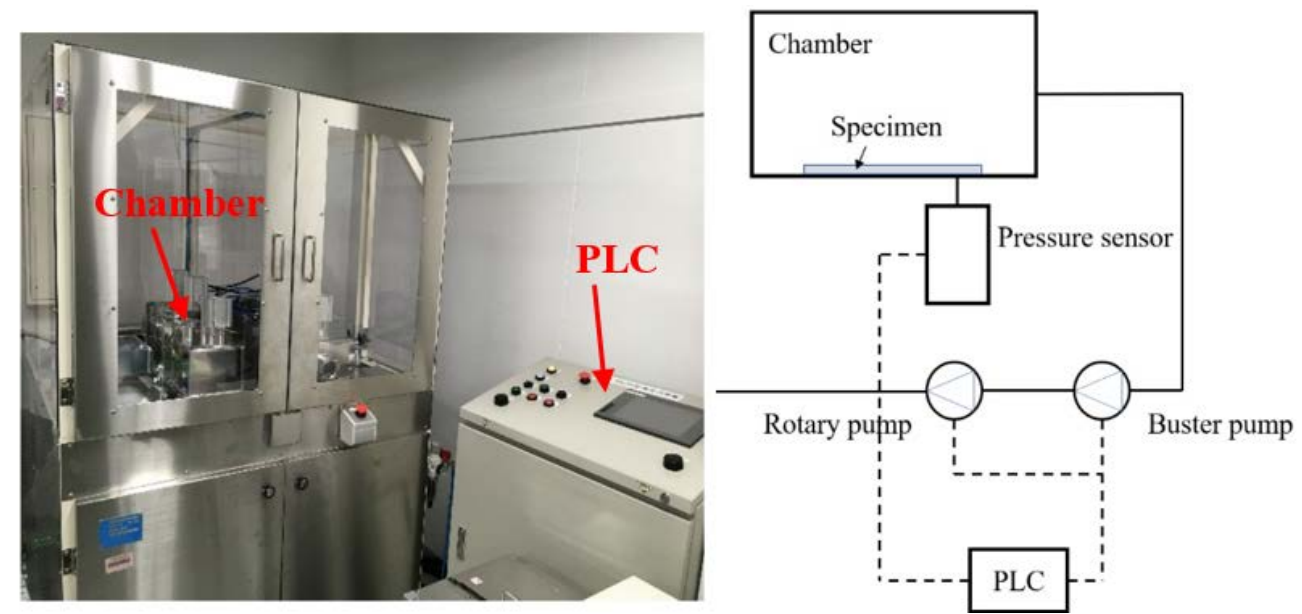

Fig. 6 Photograph and schematic of the vacuum sealing equipment.

To avoid this difficulty, four different methods are used and compared for the trial production of the frame-type VIP as examples, using the experimental setup shown in Fig. 6. The main purpose of these steps is to compare the thermal conductivity variations of the VIP with different production methods.

In these methods, outgassing from the core structure is minimised in different ways. In the first setup, Fig. 7-a, named the "normal case", the VIP is manufactured using the vacuum sealing machine in Fig. 6, and a calcium oxide adsorbent pack is used to minimise the outgassing from the core material. In the second setup in Fig. 7-b, named "vacuum drying with $\mathbf{N}_{2}$ ", the VIP structure is kept inside an environmentallycontrolled unit. In this unit, the environmental temperature is maintained at $70^{\circ} \mathrm{C}$ for $24 \mathrm{~h}$, and the structure is connected to the vacuum machine to maintain the pressure at $0.1 \mathrm{~Pa}$. This method is used to release the outgassing from the core structure. Then, nitrogen is supplied to the inside of the environmentallycontrolled unit. After that, nitrogen is exhausted from the unit. Then, the VIP structure is evacuated and sealed using the vacuum sealing machine.

In the third setup, Fig. 7-c, named "heating", a new step is proposed to reduce the time for the VIP production process. In this setup, the two flat silicon rubber heaters are used to heat up the VIP during the evacuation. This also could help the outgassing of the water vapour from the inside of the core structure. The heaters are temperature-controlled using a temperature controller, to maintain the temperature of the VIP at $70{ }^{\circ} \mathrm{C}$ during the evacuation. In the second and the third trial methods, calcium oxide adsorbent packs are also used. Finally, in the fourth production method in Fig. 7-d, named "gas adsorbent getter", an absorbent material that contains calcium oxide and alloy getter is inserted into the VIP. The calcium oxide absorbs the water vapour, while the alloy getter absorbs other gases such as nitrogen and carbon dioxide. Consequently, the pressure rise owing to the outgassing can be reduced. The results of these four trial manufacturing methods are compared in detail in Section 5.2 . 
(a) Normal case

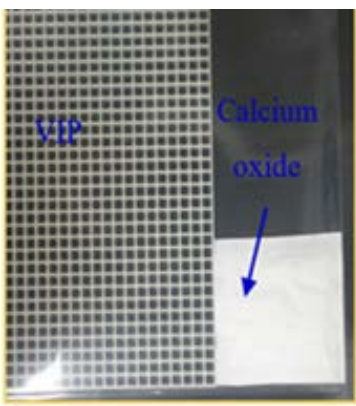

(b)Vacuum drying with $\mathrm{N}_{2}$
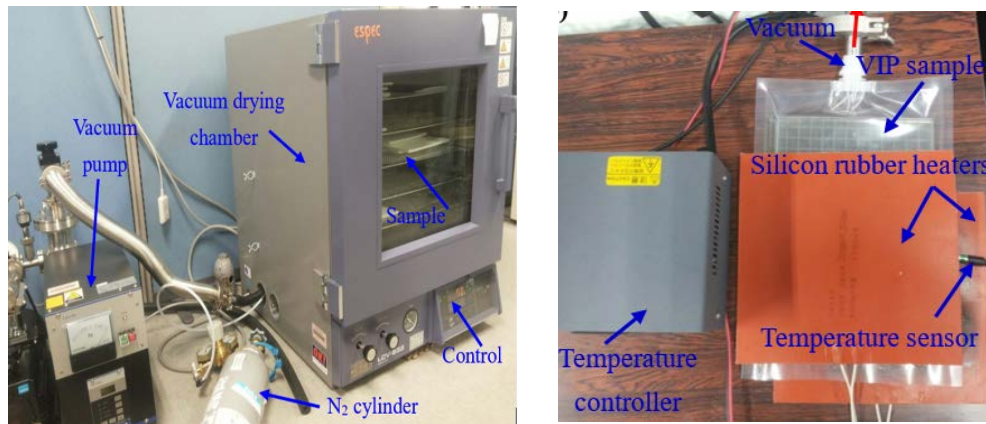

(d) Gas adsorbent

getter

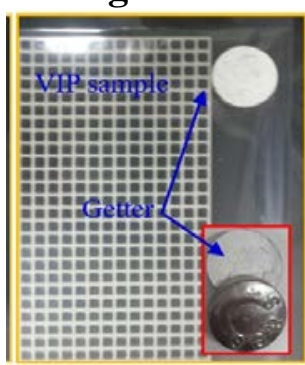

Fig. 7 Trial manufacturing methods for the frame-type VIP (a) normal method with calcium oxide adsorbent, (b) using vacuum drying chamber with $\mathrm{N}_{2}$, (c) using flat silicon rubber heaters during the evacuation, and (d) using gas adsorbent getter.

\subsection{Experimental measurements of the structured-core VIP transparency}

The schematic for light transparency measurement is depicted in Fig. 8. In this setup, the translucent VIP specimen is placed on a reflection diffuser, and is irradiated by an incandescent light source. The light source wavelength is measured to be at $800 \mathrm{~nm}$ (the maximum range for the visible wavelength), and the illuminance is measured with intensity in $\mu \mathrm{W} /\left(\mathrm{cm}^{2} . \mathrm{nm}\right)$, with and without VIP shading. The transparency ratio is defined as the ratio between the transmitted intensity in the case of using the VIP to the transmitted intensity in the case without the VIP.

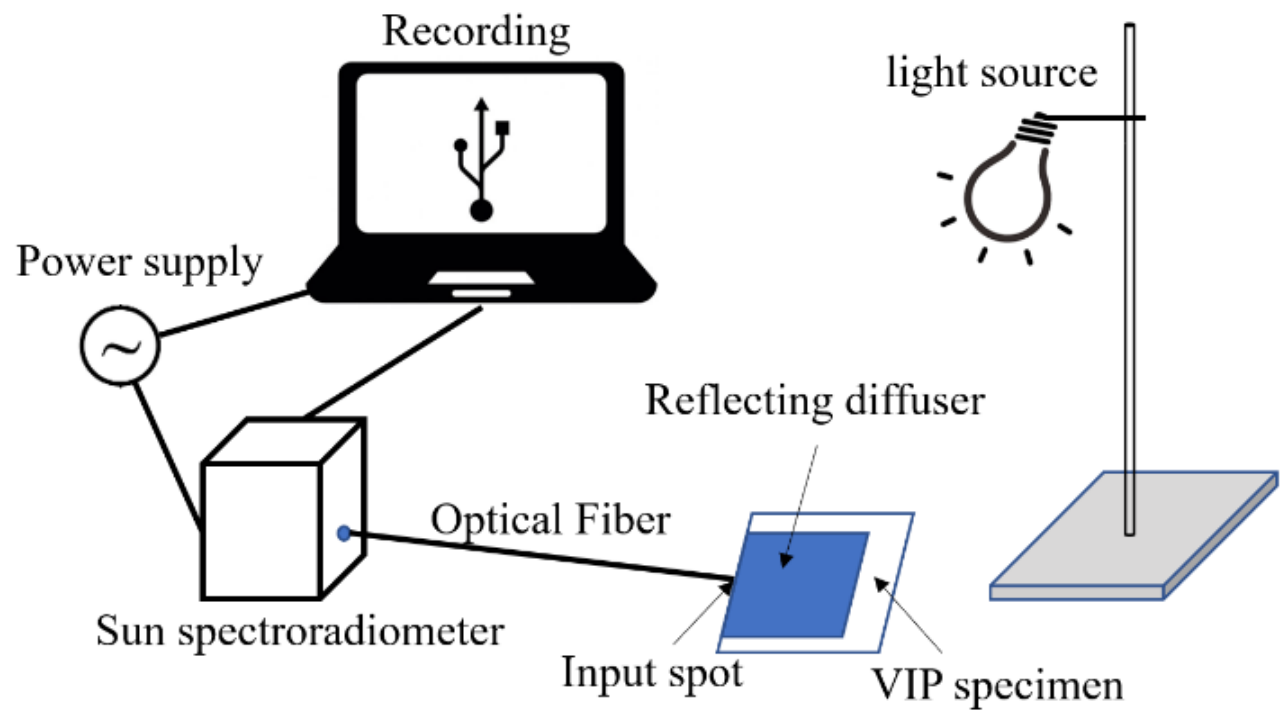

Fig. 8 Schematic of illuminance measurement. 


\section{Theoretical analysis}

In VIPs, the inner pressure must be reduced to below $10 \mathrm{~Pa}$. Increasing the gas pressure above this value rapidly increases the VIP thermal conductivity (Baetens et al., 2010). In addition, the total heat transfer in VIPs can be divided into four parts: radiation heat transfer through the vacuum space, heat conduction through the skeleton of the core of the core structure, gas conduction, and gas convection (Baetens et al., 2010). To enhance the insulation performance of the VIP, all of these parts must be minimised. However, at very low pressures, the convection can be naturally converted to pure gas conduction. Therefore, the convection can be ignored in the calculation (F. Arya et al., 2018; Choi et al., 2016). The basic governing equations used in this study are the 3D heat conduction equation, coupled with the surface-to-surface radiation model. For steady-state 3D heat conduction with a source term, "ANSYS FLUENT" solves the energy equation in the following form (“ANSYS FLUENT Theory Guide,” 2011):

$$
\nabla \cdot(k \nabla T)+S=0
$$

In the above, $T$ is the temperature, $k$ is the element thermal conductivity, and $S$ is a source term added to consider the effect of radiation in the vacuum space ("ANSYS FLUENT Theory Guide,” 2011). This equation is solved to obtain the temperature distribution and heat transfer rate through the solid layers, including the hot and cold plates' conduction and the inner structure, but without a radiation heat source. To include gas conduction in the vacuum layer, the same equation (with the radiation source term )is solved, but with the gas thermal conductivity at the designed pressure.

Air thermal conductivity is a function of the pressure and pore size (Baetens et al., 2010). This results from the exact inverse relationship between the gas pressure and the molecule-molecule collisions' mean free path. In more detail, as the gas pressure is decreased, the number of gas molecules available to transport heat is proportionally decreased. Thus, a substantial reduction in heat transfer caused by gaseous conduction occurs at low-pressure levels. To neglect gaseous conduction, the pressure within the vacuum space must be less than $0.1 \mathrm{~Pa}$ (Collins and Simko, 1998). The air thermal conductivity, $\lambda_{\mathrm{v}}$, in W/m.K, at different pressures and pore sizes, is calculated as follows (Kim and Song, 2013):

$$
\lambda_{v}=\frac{\lambda_{o}}{1+\frac{\left(1.07 \times 10^{-7}\right) T}{l_{v} P}}
$$

Here, $T, l_{v}$, and $P$ are the temperature in $\mathrm{K}$, vacuum thickness in $\mathrm{m}$, and gas pressure in $\mathrm{Pa}$, respectively. In addition, $\lambda_{o}$ is the air thermal conductivity at room temperature and pressure. In this study, it is taken as $0.026 \mathrm{~W} / \mathrm{m} . \mathrm{K}$. However, the vacuum thickness for the proposed structures changes in some locations. To incorporate this into the numerical calculations, a multi-zone approach is used. In this approach, every vacuum space with the same thickness is defined as a specific zone. Using this idea, the thermal conductivity of each zone can be calculated by knowing the thickness of the vacuum space between the hot and cold plates. For example, in frame-type spacers as seen in Fig. 9, the vacuum thicknesses in zone-1 and zone-2 are $3 \mathrm{~mm}$ and $1 \mathrm{~mm}$, respectively. Therefore, the thermal conductivities of the respective vacuum spaces in these two zones are considered to be different. The same idea is also applied for all proposed core structures where this issue exists. 
Three different techniques exist in the literature for considering the contribution of the radiation heat transfer in the vacuum space. In all of these models, an equivalent thermal conductance is calculated. This thermal conductance is dependent on the emissivity of the hot and cold sides of the VIP, and the view factor. In this case, Equation (2) is solved, without the source term. However, the vacuum space thermal conductivity is modified to include the effect of radiation. In the first technique, the equivalent radiation conductance through the vacuum space is estimated using the following correlation (Fang et al., 2009):

$$
C_{h-c, \text { radiation, } 1}=4 \varepsilon_{e f f} \sigma T_{\text {avg }}^{3}
$$

In Equation (4), $C_{h-c, \text { radiation, }, 1}, \varepsilon_{\text {eff }}, \sigma$, and $T_{\text {avg }}$ are the equivalent radiation conductance between the hot and the cold sides of the VIP in units of $\mathrm{W} / \mathrm{m}^{2}$.K., the effective emittance of the hot and cold sides of the vacuum space, a Stefan-Boltzmann constant in $\mathrm{W} / \mathrm{m}^{2} . \mathrm{K}^{4}$, and the average temperature of the vacuum space in Kelvin, respectively. The effective emittance is calculated as follows (Fang et al., 2009):

$$
\frac{1}{\varepsilon_{e f f}}=\frac{1}{\varepsilon_{h}}+\frac{1}{\varepsilon_{c}}-1
$$

Here, $\varepsilon_{h}$ and $\varepsilon_{c}$ are the emissivities of the hot and cold sides of the VIP, respectively.

In the second technique, the radiation contribution is calculated based on the principle of the heat exchange between two parallel surfaces separated by a very small gap (Incropera et al., 2007):

$$
Q_{\text {rad }}=\frac{\sigma\left(T_{h}^{4}-T_{c}^{4}\right)}{\left(\frac{1-\varepsilon_{h}}{A_{v} \varepsilon_{h}}\right)+\left(\frac{1}{A_{v} F_{h-c}}\right)+\left(\frac{1-\varepsilon_{c}}{A_{v} \varepsilon_{c}}\right)}=\frac{\sigma A_{v}\left(T_{h}^{4}-T_{c}^{4}\right)}{\left(\frac{1-\varepsilon_{h}}{\varepsilon_{h}}\right)+\left(\frac{1}{F_{h-c}}\right)+\left(\frac{1-\varepsilon_{c}}{\varepsilon_{c}}\right)}
$$

In the above, $F_{h-c}$ is the view factor between the hot and cold surfaces, and $A_{v}$ is the surface area of the panel facing either the hot or the cold side of the vacuum space, in $\mathrm{m}^{2}$. For a unity view factor, the equivalent thermal conductance owing to the radiation is calculated as following (Incropera et al., 2007):

$$
\begin{gathered}
A_{v} C_{h-c, \text { radiation }}\left(T_{h}-T_{c}\right)=\frac{\sigma A_{v}\left(T_{h}^{4}-T_{c}^{4}\right)}{\left(\frac{1}{\varepsilon_{h}}-1\right)+1+\left(\frac{1}{\varepsilon_{c}}-1\right)} \\
C_{h-c, \text { radiation }, 2}=\left(\frac{\sigma\left(T_{h}^{4}-T_{c}^{4}\right)}{\left(\frac{1}{\varepsilon_{h}}\right)+\left(\frac{1}{\varepsilon_{c}}\right)-1}\right) /\left(T_{h}-T_{c}\right)
\end{gathered}
$$

Lastly, in the third technique, the following correlation is used for the prediction of the value of $C_{h-c, \text { radiation }}$ as follows (Yang et al., 2018):

$$
C_{h-c, \text { radiation }, 3}=\varepsilon_{h} \varepsilon_{c} C_{b}\left\{\left(\frac{T_{h}}{100}\right)^{4}-\left(\frac{T_{c}}{100}\right)^{4}\right\} \frac{1}{\left(T_{h}-T_{c}\right)}
$$

In that regard, $C_{b}$ is a black body radiation constant factor, and it is set to 5.67, as proposed by (Yang et al., 2018). After the thermal conductance owing to the radiation is evaluated, the increase in the vacuum space thermal conductivity owing to the radiation effect can be estimated by multiplication of the calculated $\mathrm{C}_{\mathrm{h}-}$ c, radiation by the vacuum layer thickness. Therefore, the new thermal conductivity of the vacuum space, considering both the radiation effect and gas conduction effect, can be calculated as follows (Choi et al., 2016):

$$
\lambda_{v, \text { gas conduction }+ \text { radiation }}=\lambda_{v}+C_{h-c, \text { radiation }} l_{v}
$$


Moreover, the contribution of the radiation heat transfer rate, $\mathrm{Q}_{\mathrm{rad}}$, in watts between the two sides of the VIP is calculated using the following correlation (Fang et al., 2010):

$$
Q_{\text {rad }}=A_{v} C_{h-c, \text { radiation }}\left(T_{h}-T_{c}\right)
$$

Throughout of all these three models, the view factor between the hot and cold walls is set as unity. This is because of the smaller gap and larger facing area between the hot and cold sides of the VIP.

In the present study, a new modelling method is used to predict the contribution of the radiation effect between the hot and cold sides of the VIP. This method couples the conduction heat transfer through the vacuum space and support structure with the surface-to-surface (S-S) radiation model in the vacuum space. This model is implemented in the commercial ANSYS software (“ANSYS FLUENT Theory Guide,” 2011). The model solves Equation (2) for the vacuum space, so as to include the conduction and the radiation. This model also calculates the view factor for all contributing surfaces in the computational domain and in contact with the vacuum space. In the S-S model, the energy exchange between two surfaces depends on their size, orientation, and separation distance, which are used to calculate the view factor. These parameters are calculated automatically from the design geometry of the VIP imported by the Fluent module. This model assumes that any emission, absorption, or radiation scattering by the vacuum domain are ignored. Consequently, only the radiation from "surface-to-surface" is considered. In addition, the model assumes that the surfaces' emissivities are independent of the wavelength. This model also can be used for solar collectors' applications, radiative space heaters, and heat rejection methods in aircraft (“ANSYS FLUENT Theory Guide,” 2011). This model simultaneously solves the radiation exchange equation with the energy equation of the solid regions and the gas conduction in the vacuum space by the use of the source term for radiation, as explained in detail in the ANSYS theory guide (“ANSYS FLUENT Theory Guide,” 2011). The model results are compared with the results of previous methods in the literature in the model verification step.

In the (S-S) model, the energy flux leaving a certain surface consists of the directly-emitted energy and the reflected energy. The emitted part depends on the surface emittance. However, the reflected part depends on the incident energy flux coming from the surroundings. The last part can be considered in terms of the flux of the energy leaving all other surfaces. Therefore, the energy flux leaving from a certain surface $k$ in the VIP domain, $q_{\text {out }, k}$, can be written as follows:

$$
q_{\text {out }, k}=\varepsilon_{k} \sigma T_{k}^{4}+\rho_{k} q_{\text {in }, k}
$$

In Equation (12), $\varepsilon_{k}, T_{k}, \rho_{k}$, and $q_{i n, k}$ are the emissivity, absolute temperature, the reflectivity of the surface $k$, and the flux of energy incident from all other surfaces and received by the surface $k$, respectively. According to the grey-body model, the surface absorptivity is assumed to be the same as the surface emissivity. The amount of incident energy flux on the surface $k$ from another surface(s) $j$ is calculated as a direct function of the view factor between the surface $k$ and the surface(s) $j$. Therefore, the incident flux of energy on the surface $k$ can is calculated as follows: 


$$
q_{i n, k}=\frac{1}{A_{k}} \sum_{j=1}^{N} A_{j} q_{o u t, j} F_{j-k}
$$

Here, $A_{k}, A_{j}$, and $F_{j-k}$ are the area of the surfaces $k$ and $j$, and the view factor between the surface $j$ and surface $k$, respectively. In addition, $N$ is the total number of surfaces participating in the radiation. This number could also include the surface $k$ if the view factor between the surface $k$ and itself is not zero. The reciprocity relationship for the view factor calculation gives the following:

$$
A_{k} F_{k-j}=A_{j} F_{j-k} \quad \text { for } j=1,2,3, \ldots \ldots . . N
$$

Substituting in Equation (13), then $\mathrm{q}_{\mathrm{in}, \mathrm{k}}$ can be calculated as follows:

$$
q_{i n, k}=\sum_{j=1}^{N} q_{o u t, j} F_{k-j}
$$

Therefore, Equation (12) changes to the following:

$$
q_{\text {out }, k}=\varepsilon_{k} \sigma T_{k}^{4}+\rho_{k} \sum_{j=1}^{N} q_{\text {out }, j} F_{k-j}
$$

This equation can be written as follows:

$$
J_{k}=E_{k}+\rho_{k} \sum_{j=1}^{N} J_{j} F_{k-j}
$$

Here, $J_{k}$ is the radiant energy that is given off surface $k$, and is known as radiosity, and $E_{k}$ represents the emissive power of the surface $k$. This equation can be mathematically represented in matrix form as follows:

$$
K J=E
$$

In the above, $K$ is a matrix with $N \times N$ dimensions; $J$ and $E$ are the radiosity and emissive power vectors with length $N$ each, respectively. The view factors between the participating surfaces must be calculated first to obtain the radiosity matrix. Therefore, after importing the design of the VIP core structure, the surfaces' orientations, areas, and spacing are calculated. Then, the view factors for all of the participating surfaces are calculated using the following relationship (“ANSYS FLUENT Theory Guide,” 2011)::

$$
F_{k-j}=\frac{1}{A_{k}} \int_{A_{k}} \int_{A_{j}} \frac{\cos \theta_{k} \cos \theta_{j}}{\pi r^{2}} \delta_{k j} d A_{k} d A_{j}
$$

Here, $\delta_{k j}$ is calculated by the visibility of $d A_{j}$ to $d A_{k}$, and the value of $\delta_{k j}$ equals unity if $d A_{j}$ is visible to $d A_{k}$, and zero otherwise. Small-scale computational domains, boundary conditions, and mesh details are depicted in Fig. 9. This step is used to compare the computationally-estimated centre-of-panel thermal conductivity with the experimental results, and to evaluate the contribution of each heat transfer mode. Finally, after a solution convergence with a residual of less than $1 \times 10^{-10}$ in the energy equation is attained, the centre-of-panel thermal conductivity is numerically estimated as follows:

$$
k_{\text {eff }, \text { num. }}=\left(q_{\text {total }}\right) \times \frac{L_{v}}{\left(T_{h}-T_{c}\right)}
$$


In Equation (20), $K_{\text {eff,num }}$ and $q_{\text {total }}$ are the numerical estimated centre-of-panel thermal conductivity and the area weighted average of the total heat flux on the hot side. The latter equals that on the cold side at the converged steady-state condition, and is estimated as follows (“ANSYS FLUENT Theory Guide,” 2011):

$$
q_{\text {total }}=\frac{1}{A} \int q d A=\frac{1}{A} \sum_{i=1}^{n} q_{i}\left|A_{i}\right|
$$

Here, $n$ is the total number of elements in the selected area.

\subsection{Boundary conditions}

To solve the model-governing equations, one or more boundary conditions must be used. Therefore, Fig. 9 depicts a schematic representation of the boundary conditions used for all proposed core-structured VIPs. In more detail, to evaluate the centre-of-panel thermal conductivity, one side of the panel is maintained at a hot temperature of $35.5{ }^{\circ} \mathrm{C}$, while the other side is kept at a cold temperature of $10.5{ }^{\circ} \mathrm{C}$. The wall emissivity and temperature are defined in the vacuum zones. However, in the solid zones of the spacers, only the faces' temperatures are defined, because the radiation effect only appears in the vacuum zones. Further, the peripheral sides of the VIP are assumed to be adiabatic, owing to the symmetry of the computational domain. Finally, thermally-coupled boundary conditions are used at all interfaces. In this case, the temperature on the interfaces and the heat transfer rate are the same. The detailed mathematical expressions of the boundary conditions are presented here for the frame-type spacer as an example.

At the hot wall:

For the spacer zones $T=T_{h}$; and

For the vacuum zones $T=T_{h}$ and $\varepsilon=\varepsilon_{h}$.

At the cold wall:

For the spacer zones $T=T_{c}$; and

For the vacuum zones $T=T_{c}$ and $\varepsilon=\varepsilon_{c}$.

A mesh independence test is performed to ensure that the results are independent on the number of elements. After the test, a total of 1370521, 2450133, 1745551, 864000, and 1600000 elements are used for the prediction of the centre-of-panel thermal conductivity of the peek spacer, modified peek spacer, mesh-type, frame-type, and silica aerogel spacers, respectively. 

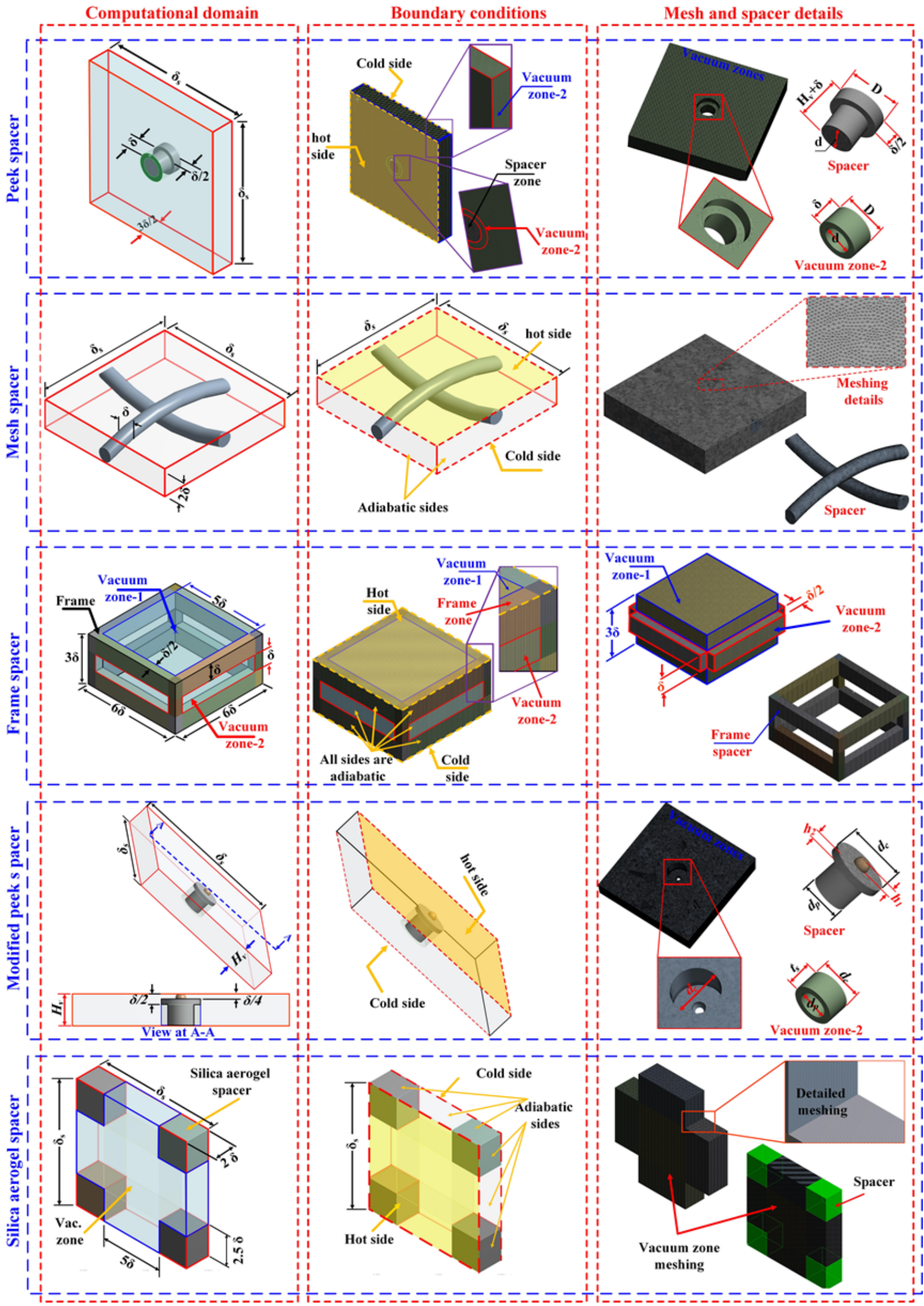

Fig. 9 Computational domains, boundary conditions, and mesh details for all investigated cases. 


\subsection{Numerical methods}

In the beginning, the computational domains presented in Fig. 9 are created using the "DesignModular" tool, and using a multizone approach. In the multizone approach, the domain is divided into several zones to enable control of the meshing, properties, and boundary conditions of each zone separately. In addition, the interfaces between each zone and the neighbouring zones were thermally coupled. Then, the computational domain is meshed. The mesh details for each core structure are displayed in Fig. 9 in the right column. The model-governing equations are solved using the Fluent module. In Fluent, the energy equation and fluid flow equations (including continuity and momentum) are standard equations, although in this work, the vacuum zones are fluid. The very low pressure allows us to neglect the convection effect and hence, the fluid flow equations can be eliminated (Fang et al., 2009, 2006; Memon et al., 2019b). However, the S-S radiations model must include a fluid zone. Therefore, the vacuum layer is considered as a fluid zone, but only the energy equation is enabled. The S-S radiation model estimates the orientation, area, and spacing of each face participating in the radiation model. Therefore, the view factors can be calculated. The energy equation for the solid layers and the energy equation for the vacuum space, including the effects of S-S radiation, are simultaneously solved. Moreover, the radiosity evaluation is performed based on the calculated view factors. To include the effects of pressure in the calculation, the vacuum region thermal conductivity with the pressure is evaluated by using Equation (3) for each vacuum zone. Shell zone conduction layers are added in the simulation to include the effects of the existing acrylic support plates. In this case, the real thickness and the thermal conductivity of the acrylic plates must be added in the simulation tool.

\subsection{Model validation}

The predicted centre-of-panel thermal conductivity is compared with the measured thermal conductivity obtained by the Experiments in Section 3.2 for the peek type spacer, mesh-type spacer, and frame-type spacer in Figs. 10-a, b, and c, respectively. Further, the currently-predicted results are compared with the numerical results of (Katsura et al., 2018), as shown in Fig. 10-d. The model is examined under different pressure values, from 0.1 to $10 \mathrm{~Pa}$. Based on the comparisons depicted in Fig. 10-a, b, and c, it is observed that the model accurately predicts the centre-of-panel thermal conductivity for the peek, mesh and frametype VIPs, with a maximum error of $11 \%$. In addition, the error is higher at lower pressures, especially in the mesh-type spacer. This may be attributed to two causes. First, at low pressure, the connections between the rods become larger, owing to the flexibility of the rods. However, this is difficult to consider in the calculation. This is also the reason that the predicted results are slightly lower than the experimental results, especially in Fig 10-b. The second cause could be gas emissivity from the core structure.

In addition, the model is validated for the silica aerogel spacer studied in (Katsura et al., 2018). In this part, the silica aerogel spacer dimensions, boundary conditions, and vacuum zone dimensions are the same as those existing in (Katsura et al., 2018), and are displayed inside Fig. 10-d. The main difference between the present model and the model developed by (Katsura et al., 2018) is that the current model is a 3D model that uses S-S radiation, whereas the model developed in (Katsura et al., 2018) is one-dimensional. Based on Fig. 10-d, an excellent agreement is observed. Although the current model nearly accomplishes the same 
results as the one-dimensional model, the heat flux, and temperature contours can be obtained by the current model, and these parameters cannot be obtained using a one-dimensional model.
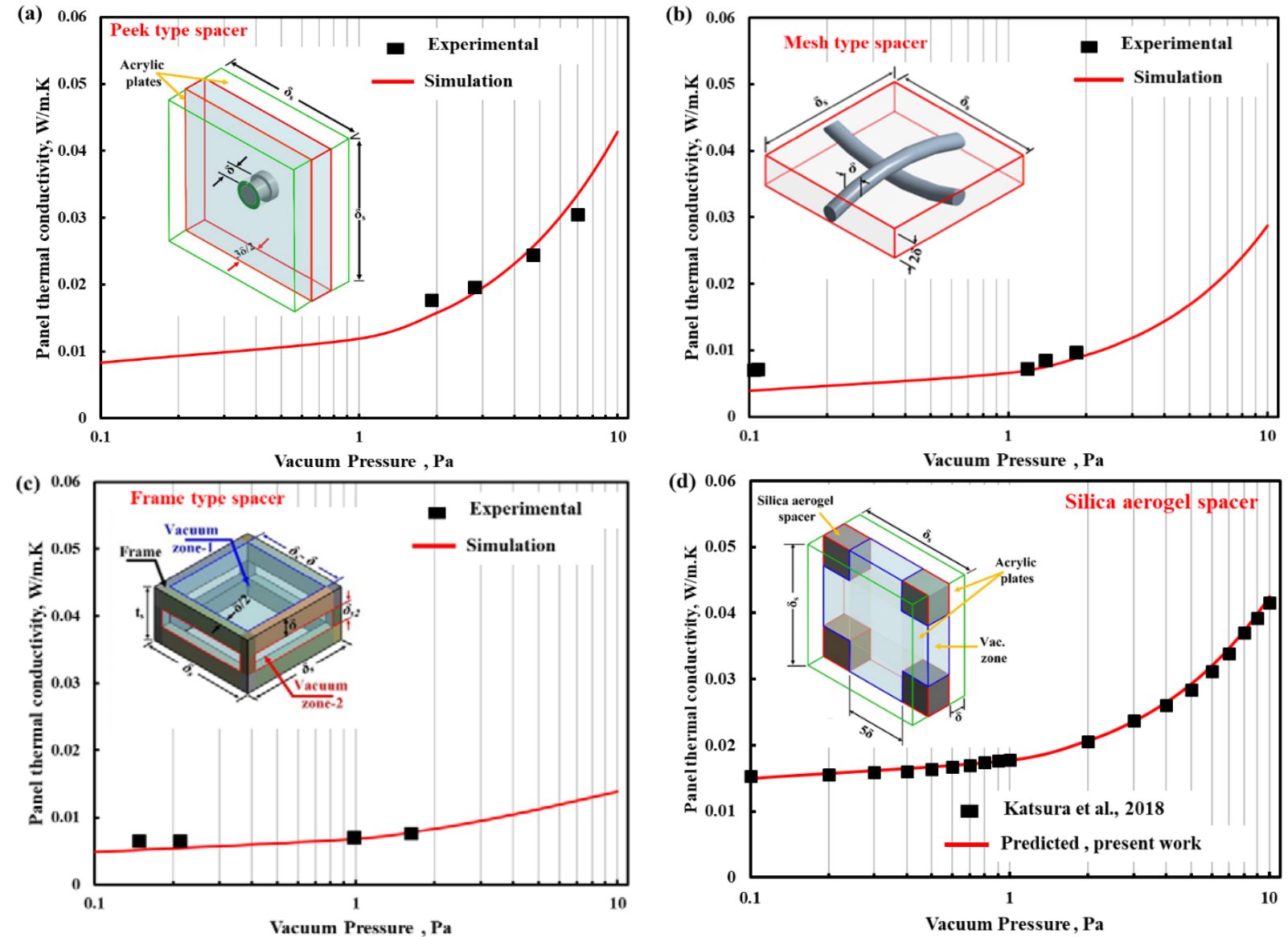

572

Fig. 10 Comparison of the predicted centre-of-panel thermal conductivities with (a) the experimental results for peek spacer; (b) the experimental results for mesh spacers; (c) experimental results of frametype spacer; and (d) the numerical results of (Katsura et al., 2018).

The S-S radiation model is compared with theoretical models using equivalent radiation conductance in the vacuum region, and the comparisons are presented in Figs. 11-a and b for the peek type and mesh-type VIPs as examples, respectively. It is evident that the S-S model accurately predicts the radiation exchange inside the VIP, as compared with the existing traditional methods using different correlations of C's. From Fig. 11-a, it can be seen that the predicted results using the S-S radiation model are very close to the results of using the models Equations (4), (8)m and (9). The estimated values of the radiation conductance using Equation (4) and Equation (9) are very close. Although the S-S radiation model considers the radiation exchange between all the surfaces in connection with the vacuum regions, the results of this model are very close to the results of using two surfaces' radiation exchanges, as proposed in Equations (4), (8), and (9) for pillar-supported VIPs. This is attributed to the fact that in VIPs, the vacuum space is very small, and the view factor between the spacer side and the radiant surfaces is also very small, owing to the smaller side area of the spacers. Therefore, the assumption of a unity view factor is a reasonable assumption, especially with smaller pillar- or peek-connection areas to the vacuum space. The maximum differences between the results of using the S-S model and other models using Equation (4) and Equation (8) are approximately $1.6 \%$ and $3.4 \%$, respectively, at the lower pressure level of $0.1 \mathrm{~Pa}$ for the peek-type spacer. However, by 
increasing the pressure, the difference decreases. This is because the radiation contribution is higher at lower pressure, and increasing the pressure increases the gas conduction. At that time, the gas conduction becomes the dominant factor. This trend will be discussed in detail in the results section, by comparing the value of each heat transfer mode.

In contrast, in the case of using a spacer with a larger surface area such as a mesh-type spacer (see Fig. 11-b), the radiation exchange between the cold and hot surface could be affected by the view factor, owing to the existence of the spacer between these two walls. To confirm this, the predicted centre-of-panel thermal conductivity using the models in Equations (4), (8), and (9) is compared with the results predicted using the S-S model. It is evident that the relative differences between the results of S-S model and the results of Equations (4) and (8) are approximately 26\% and 25.8\%, respectively, at a pressure of $0.1 \mathrm{~Pa}$. However, at higher pressures, where the gas conduction is dominant, the difference between these models decreases to approximately $2 \%$. Therefore, based on the validation step and the model comparison, the use of the S-S model accurately predicts the radiation exchange inside the VIP, by an accurate estimation of the real view factor, based on the inner spacer design. In addition, the S-S model is very sensitive to every change in the spacer design.
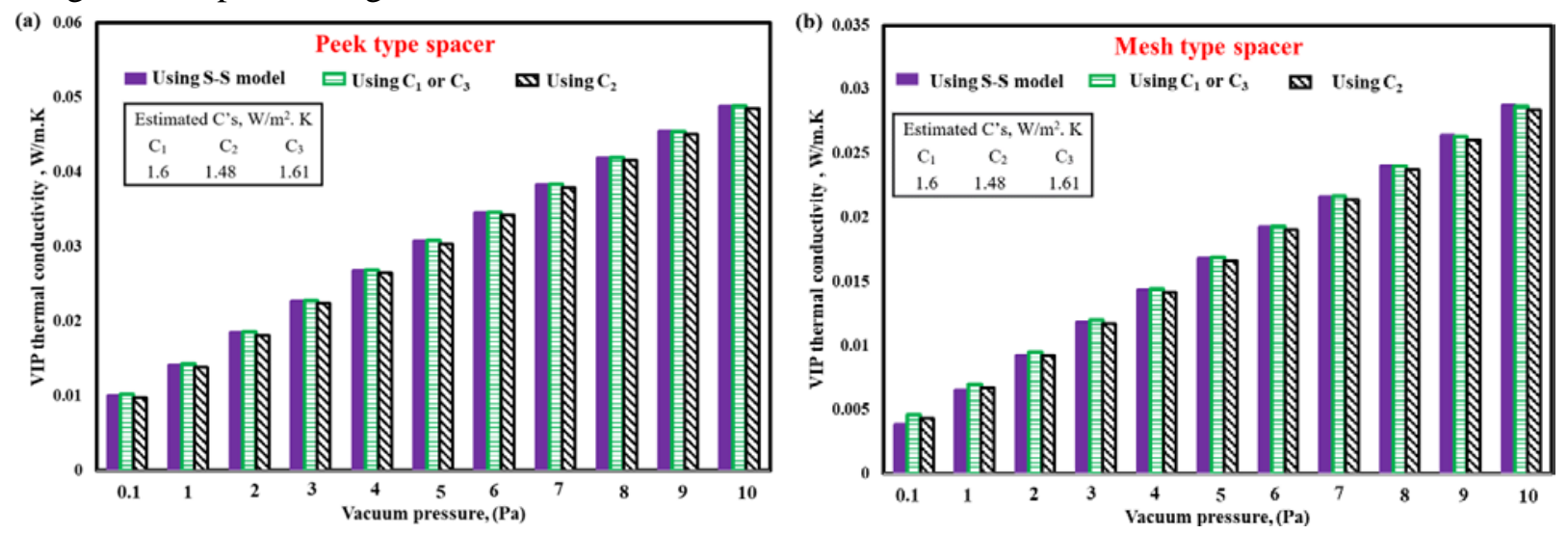

Fig. 11 Comparison of the predicted centre-of-panel thermal conductivities using surface-to-surface (S-S) radiation model with the results of using the correlations for the equivalent conductance methods available in the literature for (a) peek spacer and (b) mesh-type spacer as examples.

\section{Results and discussion}

This section is divided into four subsections. Section 5.1 evaluates and presents the effects of spacer structure on the centre-of-panel thermal conductivity at different pressures. Section 5.2 compares experimental methods for trial production of the VIP. Section 5.3 analyses an experimental evaluation of VIP light transparency, along with a cost analysis. Finally, Section 5.4 provides 3D modelling of the investigated VIPs under American Society for Testing and Materials (ASTM) boundary conditions. In addition, the annual heat gain and heat loss in two different hot and cold regions in Japan are estimated while using the investigated VIPs, as attached to existing windows.

\subsection{Centre-of-panel thermal conductivity estimation}

In all of the simulated results, the emissivities of the hot and cold walls were measured using the setup 
described in Section 3.1, and were found to be 0.28 and 0.9, respectively. The first emissivity is obtained by using the L-e coated film. However, the second emissivity is the emissivity of the acrylic plates and the core structures used in the experiments. In the simulation, all the faces coupled with the vacuum zones and the hot and cold faces are considered to participate in the S-S radiation model. In addition, the steady-state hot- and cold-side temperatures of the heat flow meter are kept constant at $35.5^{\circ} \mathrm{C}$ and $10.5{ }^{\circ} \mathrm{C}$, respectively.

The thermal conductivities of the polycarbonate spacers and acrylic plates are $0.2 \mathrm{~W} / \mathrm{m} . \mathrm{K}$ (Choi et al., 2016). However, the vacuum zones' thermal conductivity changes according to the pressure levels. At the low pressure of $0.1 \mathrm{~Pa}$ and a smaller thickness of the vacuum space of $2 \mathrm{~mm}$, the vacuum region thermal conductivity is estimated to be $2.1 \times 10^{-4} \mathrm{~W} / \mathrm{m}$.K. This means that the spacer thermal conductivity is approximately 950 times that of the vacuum region thermal conductivity. This ratio decreases to 9.5 times at a pressure of $10 \mathrm{~Pa}$. Therefore, it is expected that the conduction thermal bridge through the core structure is a vital parameter that must be considered, especially at lower pressures. Hence, to decrease the heat transfer rate through the core structure, a smaller connection is examined. This idea focuses on a reduction in the conduction area, and consequently, a reduction in the thermal bridges through the spacer. To clarify this point, a comparison is conducted for three cases of pillar-supported structures, and the results are displayed in Fig. 12. In the first case, a regular cylindrical pillar with a diameter D of $1.8 \mathrm{~mm}$ is used to obtain a vacuum gap with a thickness of $1.5 \mathrm{~mm}$. In the second case, a peek-type pillar with a head diameter $\mathrm{D}$ of $1.8 \mathrm{~mm}$, thickness $\delta / 2$ of $0.5 \mathrm{~mm}$, and nail diameter $\mathrm{d}$ of $1.2 \mathrm{~mm}$ is used. In the final case, a modified peek shape is theoretically proposed, by including a spherical head for the peek. To fix the pillars in these three structures, two acrylic plates (1 mm each) are used in the simulation. Therefore, the total thickness of the VIP in these three structures is $4.5 \mathrm{~mm}$, as presented inside Fig 12. Fig. 12 presents the variation of the VIP centre-of-panel thermal conductivity for these three cases with the pressure. It is evident that the new modified peek attains a lower centre-of-panel thermal conductivity over the full range of the pressure, i.e. from $0.1 \mathrm{~Pa}$ to $10 \mathrm{~Pa}$. This because in the modified peek support, the connection between the hot and cold walls is decreased by using the hemispherical head, in addition to reducing the support diameter from 1.8 $\mathrm{mm}$ to $1.2 \mathrm{~mm}$.

In more detail, the centre-of-panel thermal conductivity is reduced by approximately $37 \%$ and $5.9 \%$ at pressures of $0.1 \mathrm{~Pa}$ and $10 \mathrm{~Pa}$, respectively, with changing the conventional common cylindrical pillar to the modified peek pillar. This reduction is attributed to the reduction in the conduction heat flux, as presented in Fig. 13. In this figure, the variations of the conduction and radiation heat fluxes are displayed for the pillar-supported designs at different pressures in Figs. 13-a and b, respectively. The area-weighted average of the total heat transfer rate from the hot surface is estimated and divided by the total surface area of the hot wall to obtain the total heat flux from the hot wall. After that, the area-weighted average of the net radiation heat transfer rate from the hot wall is also calculated, and the radiation heat flux is estimated by the dividing this value to the surface area of the hot wall. Finally, the conductive heat flux is estimated by the subtraction of the radiation heat flux from the total heat flux. The predicted conduction heat flux considers both the pillar conduction and the gas conduction in the vacuum space. 
Based on Fig. 13-a, a significant reduction in the conduction heat flux is predicted while using the modified peek pillar support structure, especially at lower pressures. This may be attributed to two factors.

\section{2}

663

664

665

666

667

668

669

670

671

672

673

674

675

676

677

678

679

680

681

682

683

The first is the reduction in the connection area between the hot and the cold walls. The second reason is that a very thin layer of low conductive vacuum exists between the top plate and the pillar circular head in the modified peek support, but does not exist in the cylindrical pillar support. This layer, with a thickness of $\delta / 2$, has a very low thermal conductivity as compared with the pillar conductivity of $0.2 \mathrm{~W} / \mathrm{m} . \mathrm{K}$. Therefore, a smaller conductive heat transfer could be attained. This reduction decreases with the pressure increase, because increasing the pressure increases the conduction through this very thin layer of the vacuum space. Consequently, it increases the VIP thermal conductivity. In more detail, at $0.1 \mathrm{~Pa}$, changing the cylindrical pillar support to the modified peek support decreases the conduction heat flux from $35 \mathrm{~W} / \mathrm{m}^{2}$ to approximately $5.6 \mathrm{~W} / \mathrm{m}^{2}$.

Meanwhile, the radiative heat flux is presented in Fig. 13-b. It is predicted that the radiative heat flux slightly decreases with an increase in pressure. This is attributed to the observation that at higher pressures, a higher conduction heat flux is obtained. This decreases the temperature differences between the inner surfaces in connection with the vacuum regions. Thus, a reduction in the radiative heat flux could be attained. This reduction is very small compared with the increase in the conduction heat flux. In more detail, with an increase in the pressure from 0.1 to $10 \mathrm{~Pa}$, the conduction heat flux increases from 5.9 to $230 \mathrm{~W} / \mathrm{m}^{2}$, whereas the radiation heat flux decreases from $38.6 \mathrm{~W} / \mathrm{m}^{2}$ to $33.5 \mathrm{~W} / \mathrm{m}^{2}$. In addition, the radiation heat flux in the case of using the modified peek support is higher than that when using the cylindrical support. This because of the increase in the vacuum region with the use of the modified peek support; the radiative heat flux increases from 37.1 to $38.9 \mathrm{~W} / \mathrm{m}^{2}$ when replacing the cylindrical pillar with the modified peek pillar at a pressure of $0.1 \mathrm{~Pa}$.

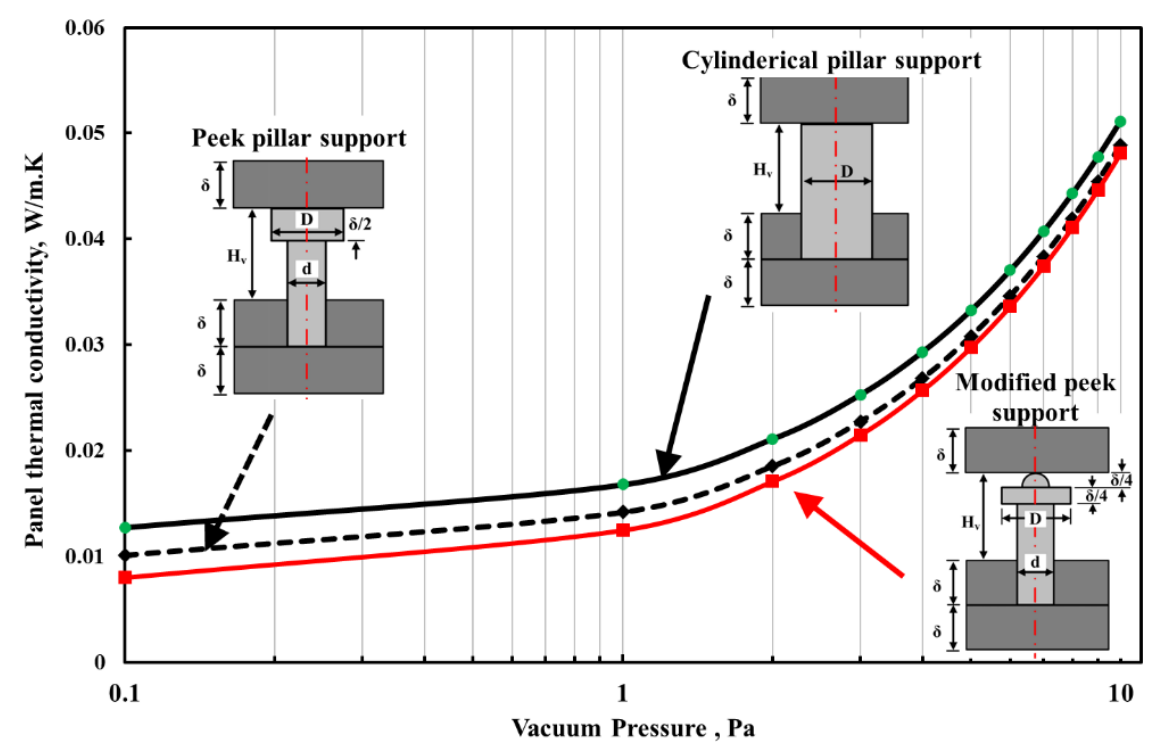

Fig. 12 Variation of the predicted centre-of-panel thermal conductivity with the internal pressure for three different designs of pillar-supported VIPs. 

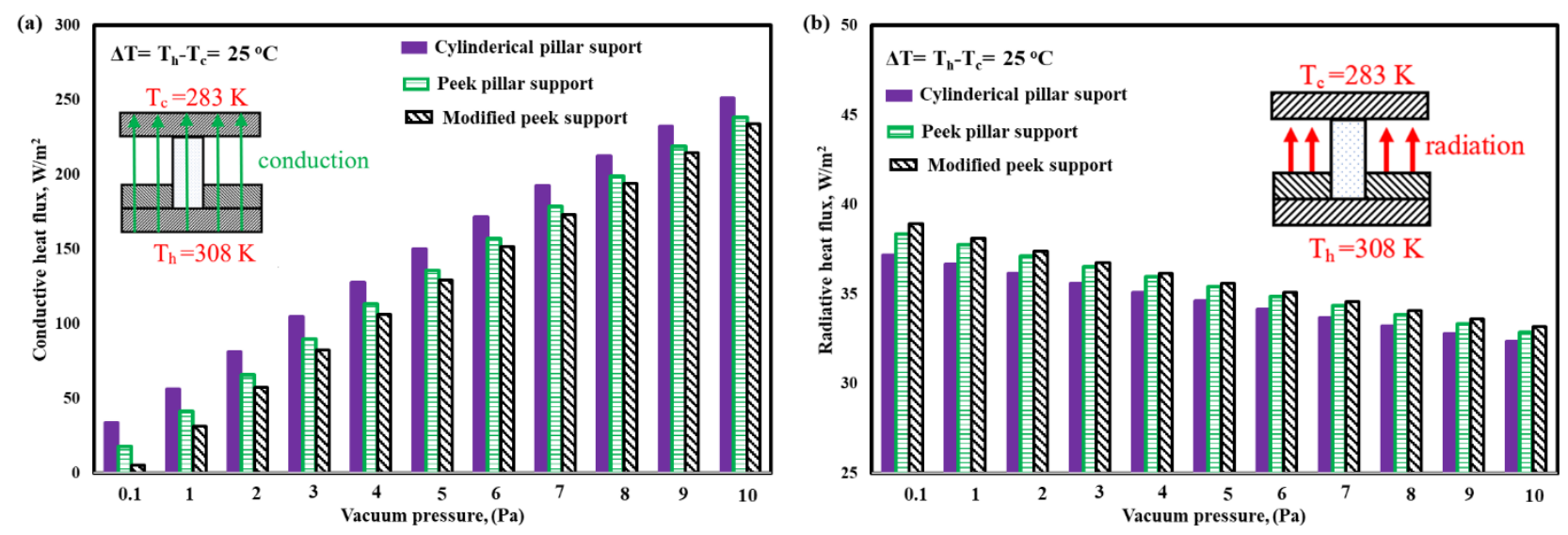

Fig. 13 Variation of (a) conductive heat flux and (b) radiative heat flux with the pressure levels for the three investigated pillar-supported structures.

At the beginning of the modelling, the mesh-type spacer is simplified and modelled as a round plusshaped spacer, as seen in Fig. 14 (left side). The predicted centre-of-panel thermal conductivity, in this case, is compared with the experimental results. In this case, the computational fluid dynamic meshing is easier and faster than in an actual case. However, it is found the predicted results are higher than the experimental results. This because the connection between the spacer and the hot wall is larger than in the real case. Therefore, the real case for the mesh spacer is modelled, and the results are compared with the experiments. A good agreement is found, as discussed earlier in the validation step. Therefore, the actual mesh shape as presented in Fig. 14 (right side) is considered through the entirety of this work.

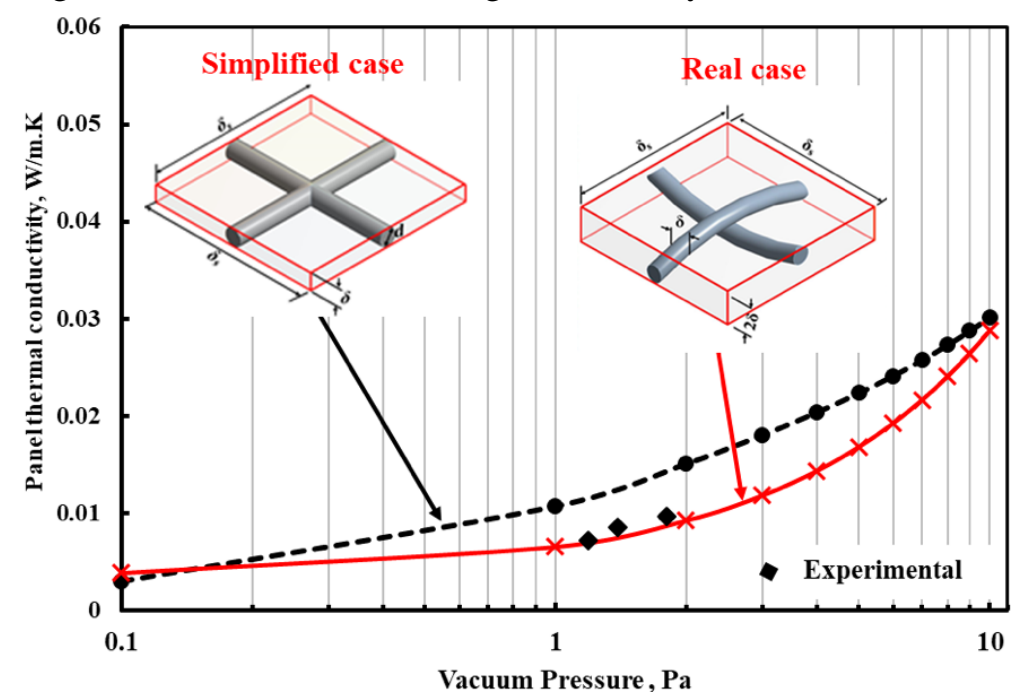

Figure 15-a compares the variation of the centre-of-panel thermal conductivity for all investigated core structures at different pressure levels. From this figure, three findings can be determined. First, increasing the pressure increases the centre-of-panel thermal conductivity. Second, although the silica aerogel spacer has a lower thermal conductivity of $0.02 \mathrm{~W} / \mathrm{m} . \mathrm{K}$, the silica aerogel VIP accomplished the highest centreof-panel thermal conductivity among these structures at lower pressure levels. This because in the silica 
aerogel spacer, the ratio of the area occupied by the silica aerogel to the total area of the panel is approximately $25 \%$, and the remaining $75 \%$ is occupied by vacuum. Therefore, this increase in silica aerogel area eliminates the benefit of its lower thermal conductivity as compared with other spacers. Therefore, a compromise between the heat transfer area and the spacer thermal conductivity is essential. However, the silica aerogel spacer cannot be easily manufactured in the form of other proposed structures, owing to its brittle structure with a low yield strength, which could lead to the VIP fracturing during the fabrication (Ma et al., 2018; Woignier et al., 2015). Finally, at low pressures below 1 Pa, the mesh-type and frame-type spacers attain the lowest panel thermal conductivity, at approximately $0.007 \mathrm{~W} / \mathrm{m} . \mathrm{K}$. This is attributed to the reduction in thermal bridge attained in the spacer. In particular, in the mesh-type spacer, the connection area between the hot and cold side of the VIP is very small. For more clarification, Fig 15b shows the variation of the centre-of-panel thermal conductivity with the pressure in a "zoomed in" smaller range, from $0.1 \mathrm{~Pa}$ to $3 \mathrm{~Pa}$.
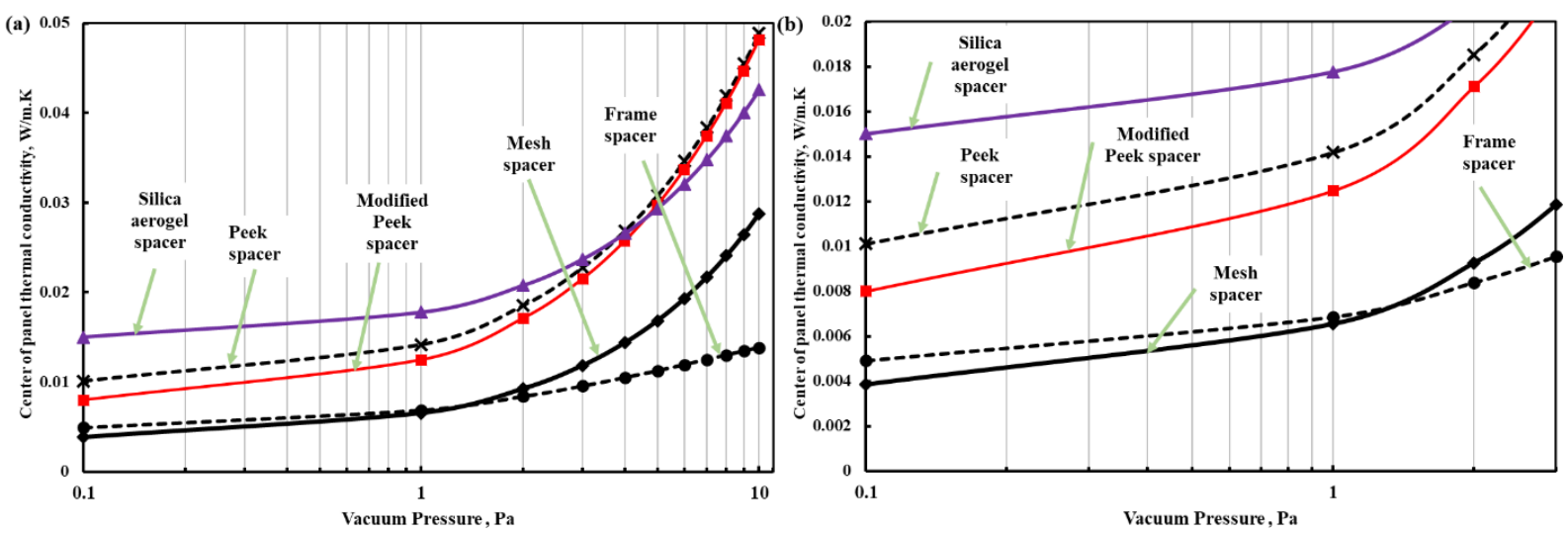

Fig. 15 Variation of the predicted centre-of-panel thermal conductivity (a) for vacuum pressure from 0.1 to $10 \mathrm{~Pa}$ and (b) for vacuum pressure from 0.1 to $3 \mathrm{~Pa}$ for all the structured-core transparent VIPs.

Figs. 16-a and b show the variations of conductive heat flux and radiative heat flux attained in the studied VIPs, respectively. Generally, in Fig. 16-a, at pressures above $2 \mathrm{~Pa}$, although the mesh spacer attains the highest conductive heat flux, it accomplishes the lowest VIP thermal conductivity. This because of the small thickness of this panel, at $2 \mathrm{~mm}$. Similarly, at a pressure of $0.1 \mathrm{~Pa}$, although the modified peek spacer has the lowest conductive heat flux, it does not attain the lowest VIP thermal conductivity. This is attributed to the fact that in pillar-supported VIPs, the total VIP thickness is much higher. This larger thickness increases the effective thermal conductivity. In more detail, in pillar-supported spacers, the total VIP thickness is 4.5 $\mathrm{mm}$, whereas for the mesh-type spacer, it is approximately $2 \mathrm{~mm}$. This means that for the same total heat flux, the thermal conductivity of the pillar-supported VIP will be 2.25 times that of the mesh-type spacer. This is one of the main drawbacks of the pillar-supported VIPs mentioned in this work. The other drawback is that the manufacturing process is very difficult as compared with the other types of spacers, such as meshtype spacers. From Fig. 16-b, it can be observed that the radiation heat flux decreases slightly for all investigated VIPs with an increase in pressure. Moreover, the frame-type and silica aerogel spacers obtained the lowest radiative heat flux. This is because in these spacers, the vacuum area in connection with the hot wall is at a minimum. This is also why the pillar-supported VIPs attain the maximum radiation heat flux, 

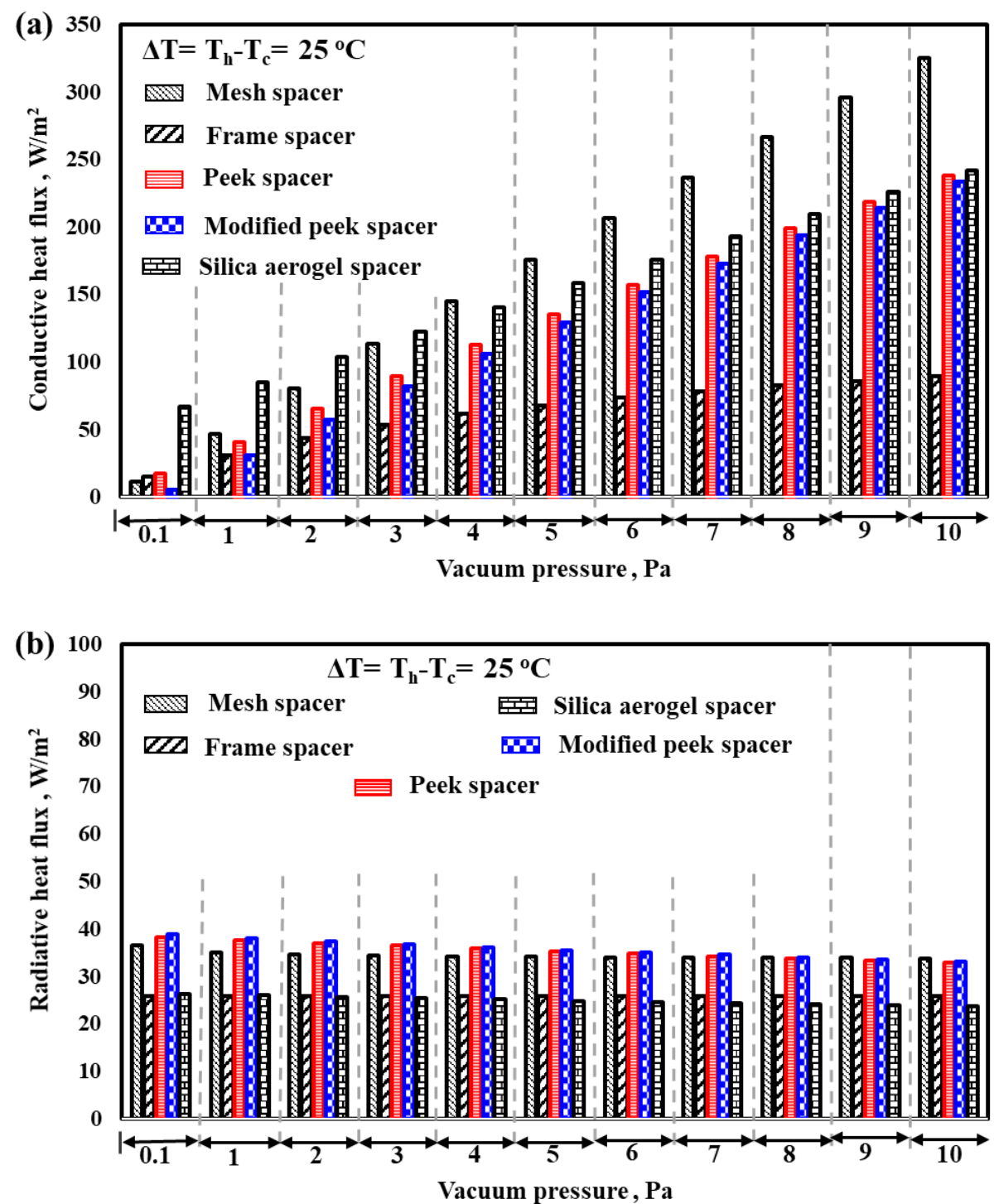

Fig. 16 Variations in (a) conductive heat flux and (b) radiative heat flux with pressure for the investigated VIPs.

\subsection{Trial production methods of VIP}

In Fig. 17-a, the predicted thermal conductivity variation with time is displayed for the four trial production methods explained in Section 3.3. The comparison is implemented for the frame-type VIP as an example. It is evident that using getter material during the manufacturing process of the VIPs accomplishes the lowest thermal conductivity in comparison with the use of other methods. In addition, the direct manufacturing of the VIP without the use of a calcium oxide adsorbent pack is the worst case. As the use of the getter accomplished the best results among these methods, a further trial method is implemented here to compare the predicted thermal conductivity of the frame-type VIP in the case of using two different types of outgassing adsorbent materials. The getter material is compared with the use of a calcium oxide desiccant inside a pack. The results are recorded for 75 h, and are displayed in Fig. 17-b. It is noticeable that the use of getter material accomplished the lowest panel effective thermal conductivity in comparison with the use 
of calcium oxide desiccant packs. The lowest thermal conductivity attained in the case of using getter was approximately $0.011 \mathrm{~W} / \mathrm{m} . \mathrm{K}$, which is equivalent to $5 \mathrm{~Pa}$. This means that the inside pressure increased after the sealing, owing to the gas emissivity. The effect of this parameter will be investigated in the authors' future work.
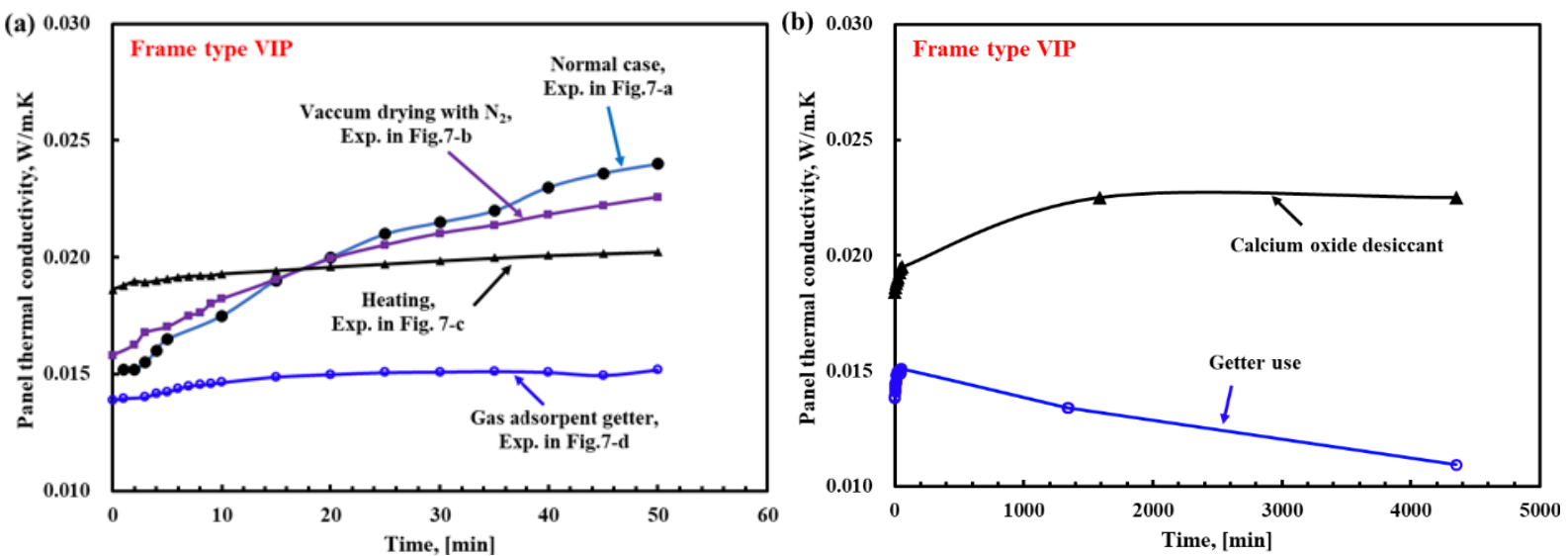

Fig. 17 variation of the centre-of-panel thermal conductivity with the elapsed time for (a) different trial manufacturing methods and (b) different two outgassing adsorbent materials.

\subsection{Light transparency and cost analysis}

This section presents the transparency measurements of the proposed VIPs, and the cost analysis. Table 3 displays the measured transparency of the manufactured VIPs with different core structures. In this experiment, the illuminance is measured with and without VIP shading. The ratio displayed in the table represents the measured light intensity in a case with the VIP to a reference case where no VIP exists. Here, it is worth mentioning that the measured transparency is only for the VIPs without the single-layered glass window of $3 \mathrm{~mm}$. It is evident that the transparency of the manufactured VIPs ranges from 0.65 to 0.9 , for the mesh-type spacer to the cylindrical-pillar spacer, respectively. In addition, as the modified peek spacer is only numerically investigated, the expected transparency could be similar to that of the peek type spacer.

Table 3. Measured transparency for the experimentally-examined VIPs

\begin{tabular}{cccccc}
\hline Conditions & $\begin{array}{c}\text { Without } \\
\text { VIP }\end{array}$ & $\begin{array}{c}\text { Silica } \\
\text { aerogel } \\
\text { spacer }\end{array}$ & $\begin{array}{c}\text { Peek } \\
\text { type } \\
\text { spacer }\end{array}$ & $\begin{array}{c}\text { Mesh- } \\
\text { type } \\
\text { spacer }\end{array}$ & $\begin{array}{c}\text { Frame- } \\
\text { type } \\
\text { spacer }\end{array}$ \\
\hline $\begin{array}{c}\text { Intensity } \\
\left(\mu W / \mathrm{cm}^{2} / \mathrm{nm}\right) \\
\text { Transparency } \\
\text { Ratio }\end{array}$ & 20000 & 14000 & 17500 & 13000 & 15000 \\
\hline
\end{tabular}

The cost of the proposed VIPs is compared with the most common insulating method, which uses vacuum double-glazing insulation technology. The comparison is made for a $1 \mathrm{~m}^{2}$ window, and is presented in Fig. 18. Further, the cost of the VIPs includes the cost of all of the used materials, including the envelope, spacers, and L-e coating films, as presented in detail in Table 4. Based on the available data, it is evident that the insulation cost of using VIPs represents approximately one-third of the cost of an insulation method using double-glazing. In addition, the idea proposed in this work can be effectively applied to the windows 
of existing buildings by attachment or by using it as a curtain, with a very low cost as compared to the use of silica aerogel VIPs. Finally, based on Table 4, it is evident that the L-e film represents approximately half the price of the VIP.

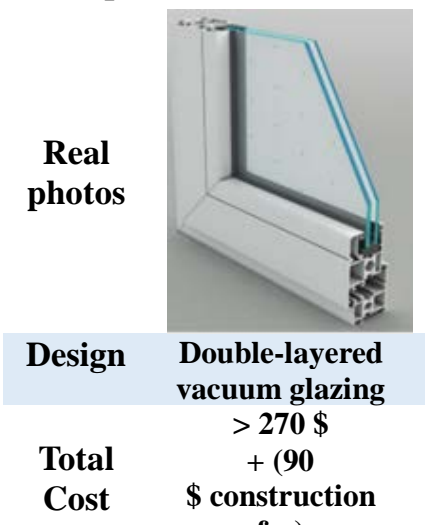

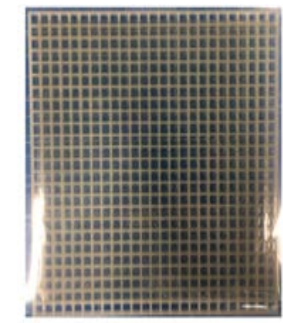

Frame VIP

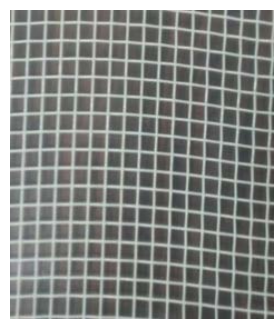

Mesh VIP

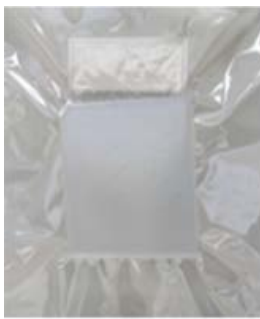

Silica aerogel VIP

$>4500 \$$

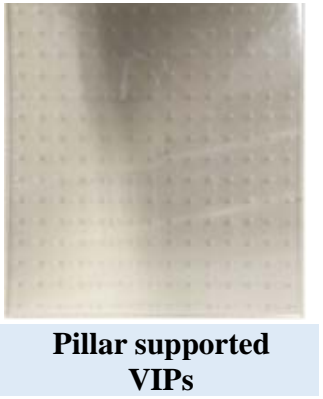

$<135 \$$ fee)

Fig. 18. Comparison of the calculated production cost of proposed VIPs with the double-layered vacuum glazing insulation.

Table 4 Detailed costs of the manufactured VIPs $\left(\$ / \mathrm{m}^{2}\right)$

\begin{tabular}{ccccc}
\hline Item & Mesh spacer & Frame spacer & Peek spacer & Silica aerogel \\
\hline Core material & $9 \$$ & $18 \$$ & 36 \$ (plates + pillars) & $4401 \$$ \\
L-e film & $45 \$$ & $45 \$$ & $45 \$$ & $45 \$$ \\
Envelope & $18 \$$ & $18 \$$ & $18 \$$ & $18 \$$ \\
Manufacturing & $18 \$$ & $18 \$$ & $36 \$$ & $36 \$$ \\
fee + adsorbent & $90 \$$ & $99 \$$ & $135 \$$ & 4500 \\
\hline Total cost & 90 &
\end{tabular}

\subsection{Energy analysis}

This section evaluates the thermal performance when attaching the proposed VIPs to a $3 \mathrm{~mm}$ singlelayered glass window, based on the ASTM standards (Section 5.4.1), and based on real meteorological conditions (Section 5.4.2).

\subsubsection{Thermal performance analysis under American Society for Testing and Materials (ASTM) boundary conditions}

In this section, the developed 3D model is solved for the proposed VIPs when attached to a conventional glass window with a $3 \mathrm{~mm}$ thickness. The aim of this section is to estimate the temperature contours, heat flux transfer, and U-value of the system. The schematic of the modelled system consists of a $3 \mathrm{~mm}$ glass layer attached to the VIPs, as shown in Fig. 19. The boundary conditions are used as recommended by the ASTM standards for winter conditions, and as used by (Fang et al., 2009). In these boundary conditions, the indoor and outdoor ambient air temperatures were assumed constant at 21.1 and $-17.8{ }^{\circ} \mathrm{C}$, respectively. In addition, the convective heat transfer coefficients on the inside and the outside surfaces of the VIP with the glass window were set to be 8.3 and $30 \mathrm{~W} / \mathrm{m}^{2} . \mathrm{K}$, respectively.

The predicted 3D isotherms on the vacuum space at a vacuum pressure of $0.1 \mathrm{~Pa}$ are presented in Fig. 19. Fig. 19 shows that a substantial temperature difference prevails between the two sides of the vacuum 
layer. The highest temperature difference is accomplished for the mesh-type spacer. In addition, the use of a mesh-type VIP attached to the existing window with $3 \mathrm{~mm}$ single-layered glass thickness decreases the U-value from 6.3 to $1.14 \mathrm{~W} / \mathrm{m}^{2} . \mathrm{K}$. This substantial reduction in the U-value decreases the heat loss from the building. In addition, by using the silica aerogel spacer, a higher U-value is obtained. This because high heat is transferred through the silica aerogel spacer, as previously explained and predicted using the temperature contours.

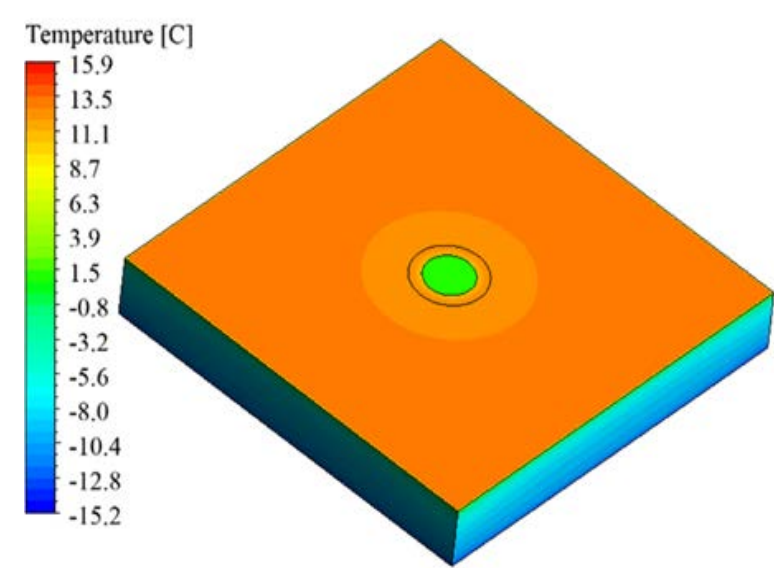

Peek type spacer $\mathrm{q},\left(\mathrm{W} / \mathrm{m}^{2}\right)$

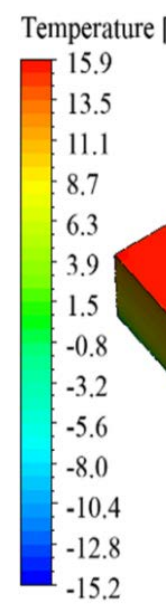
61.57 15.2

$$
\left(\mathrm{W} / \mathbf{m}^{2} . \mathrm{K}\right)
$$
1.58

\section{re $[\mathrm{C}]$}

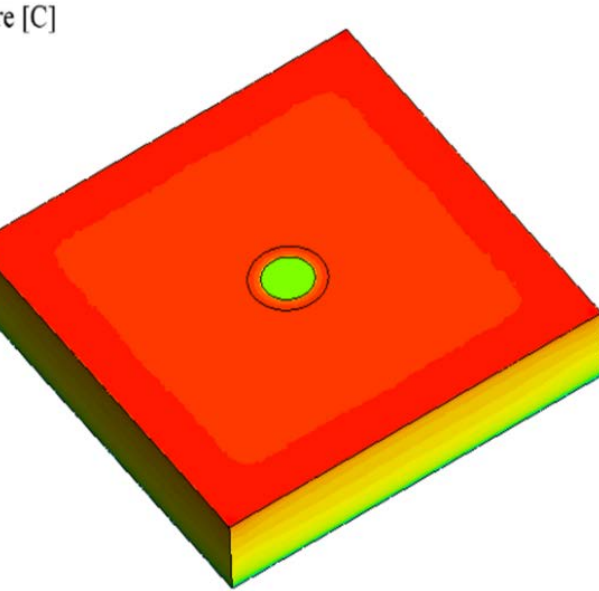

Modified peek spacer q, $\left(\mathrm{W} / \mathbf{m}^{2}\right)$ 45.9

$$
\mathrm{U}_{\text {value, }}\left(\mathrm{W} / \mathrm{m}^{2} \cdot \mathrm{K}\right)
$$

1.18

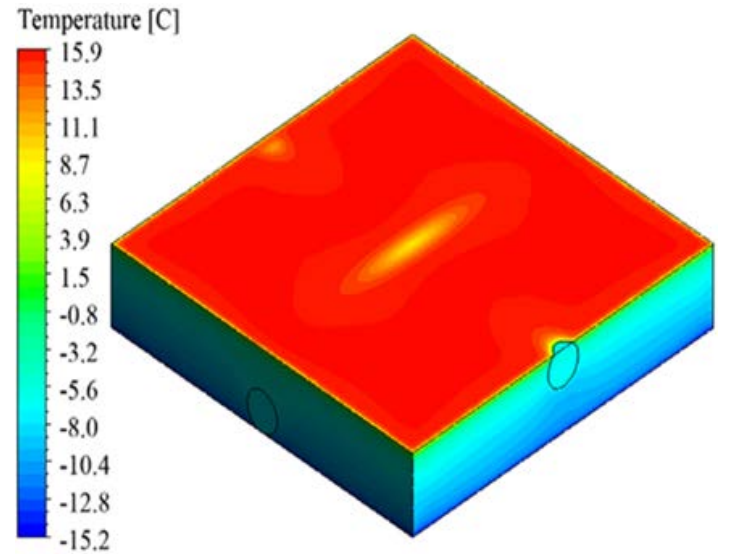

Mesh-type spacer $q,\left(W / \mathbf{m}^{2}\right) \quad U_{\text {value, }}\left(\mathrm{W} / \mathrm{m}^{2} . \mathrm{K}\right)$ 44.4 Temperature [C]
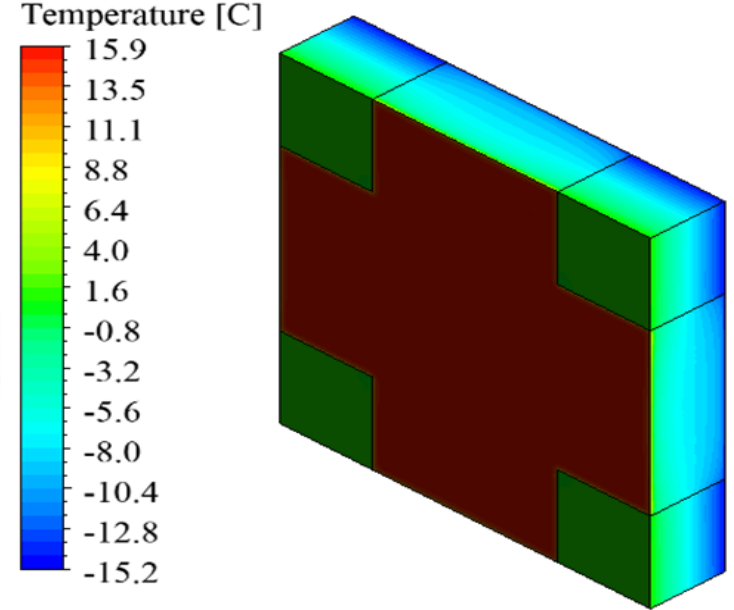

Silica aerogel spacer

$$
\begin{array}{cc}
\mathbf{q},\left(\mathrm{W} / \mathrm{m}^{2}\right) & \mathrm{U}_{\text {value }},\left(\mathrm{W} / \mathrm{m}^{2} . \mathrm{K}\right) \\
\mathbf{7 1 . 5} & \mathbf{1 . 8 3 8}
\end{array}
$$

Fig. 19 Predicted 3D temperature contours of the investigated VIPs using American Society for Testing and Materials (ASTM) boundary conditions.

\subsubsection{Annual energy analysis}

This section is used to estimate the hourly and total annual thermal energy transferred through the proposed VIP when attached to the $1 \mathrm{~m}^{2}$ single-layered glass window with $3 \mathrm{~mm}$ thickness. Moreover, the total rates of thermal energy transferred with and without the use of VIPs are compared. In this calculation, the inner air temperature is assumed to be at $20{ }^{\circ} \mathrm{C}$, with an inside convective heat transfer coefficient of 7.7 W/m².K (Fang et al., 2010; Memon et al., 2019b). In addition, the calculation uses the actual ambient temperatures and wind speed in Japan, by examining Ishigaki island $\left(24.41^{\circ} \mathrm{N}, 124.17^{\circ} \mathrm{E}\right)$ as a hot region, 
and Sapporo, Hokkaido (43.06 $\left.{ }^{\circ} \mathrm{N}, 141.35^{\circ} \mathrm{E}\right)$ as a cold region. The hourly ambient temperature and wind speed are presented in Figs. 20-a and b, respectively. These meteorological conditions are measured by the authors for Ishigaki, and are downloaded from Japan Meteorological Agency website for Sapporo. In-house MATLAB code is developed to estimate the hourly and the annual thermal energy transfer. The model adopted in this section is a one-dimensional quasi-steady model. This model is an efficient for a long-term energy evaluation, as it predicts results with reasonably accepted accuracy in a short period of time. In this model, the contact thermal resistance effect between the VIP and the glass window is not considered in the calculation. In addition, it is also assumed that no solar radiation strikes the exterior surface of the window. Therefore, the sol-air effect is neglected. The steady-state conduction heat flux transfer from the outside to the interior of the building through the VIP-glass window system is calculated as follows:

$$
q=\frac{\left(T_{a}(t)-T_{i}\right)}{\left(\frac{1}{h_{c, i}}+\frac{\delta_{g}}{k_{g}}+\frac{\delta_{v}}{k_{v}}+\frac{1}{h_{c, o}(t)}\right)}
$$

In the above, $q, \delta_{g}, k_{g}, \delta_{v}, k_{v}$, and $h_{c, i}$ are the rate of total thermal heat flux transfer in $\mathrm{W} / \mathrm{m}^{2}$, glass thickness in $\mathrm{m}$, glass thermal conductivity in W/m.K, VIP thickness in $\mathrm{m}$, VIP thermal conductivity in W/m.K, and the inside convective heat transfer coefficient in $\mathrm{W} / \mathrm{m}^{2} . \mathrm{K}$, respectively. A negative value of $q$ denotes a heat loss from the building, which occurs when the outside temperature is less than the inside designed temperature. Instead of using a constant for the outside convective heat transfer coefficient during the simulation, it is taken from the wind speed and ambient temperature-dependent equation derived by Nusselt-Jürges, and described in detail in (Palyvos, 2008). This equation is written for smooth surfaces, such as the exterior surfaces of windows, as follows (Palyvos, 2008):

$$
\begin{aligned}
& h_{c, o}(t)=5.678\left\{0.99+0.21 \times\left[\left(\frac{294.26}{273.16+T_{a}(t)}\right) \times \frac{U_{\infty}(t)}{0.3048}\right]\right\} \quad \text { at } U_{\infty}(t)<4.88\left(\frac{m}{s}\right) \\
& h_{c, o}(t)=5.678\left\{0.5 \times\left[\left(\frac{294.26}{273.16+T_{a}(t)}\right) \times \frac{U_{\infty}(t)}{0.3048}\right]^{0.78}\right\} \quad \text { at } 4.88 \leq U_{\infty}(t)<30.48\left(\frac{m}{s}\right)
\end{aligned}
$$

Here, $h_{c, o}(t), T_{\mathrm{a}}(\mathrm{t})$, and $U_{\infty}(t)$ are the hourly convective heat transfer coefficient from the exterior surfaces of the window in $\mathrm{W} / \mathrm{m}^{2} . \mathrm{K}$, the ambient temperature variation with the time in ${ }^{\circ} \mathrm{C}$, and the wind speed in $\mathrm{m} / \mathrm{s}$, respectively. The constants in Equation (23) are empirical constants derived from the experiments developed by Nusselt-Jürges. Table 5 shows the thicknesses of the VIPs with the relevant thermal conductivities at a pressure of $1 \mathrm{~Pa}$.

Table 5 Detailed thickness and centre-of-panel thermal conductivities of the investigated VIPs at $1 \mathrm{~Pa}$

\begin{tabular}{ccccccc}
\hline & $\begin{array}{c}\text { Peek } \\
\text { spacer }\end{array}$ & $\begin{array}{c}\text { Mesh } \\
\text { spacer }\end{array}$ & $\begin{array}{c}\text { Cylindrical } \\
\text { pillar }\end{array}$ & $\begin{array}{c}\text { Frame } \\
\text { spacer }\end{array}$ & $\begin{array}{c}\text { Modified } \\
\text { peek spacer }\end{array}$ & $\begin{array}{c}\text { Silica } \\
\text { aerogel }\end{array}$ \\
\hline Thickness, (mm) & 4.5 & 2 & 4.5 & 3 & 4.5 & 4 \\
$k_{v} @ 1 \mathrm{~Pa},(\mathrm{~mW} / \mathrm{m} . \mathrm{K})$ & 14.2 & 6.5 & 16.7 & 6.8 & 12.4 & 17.7 \\
\hline
\end{tabular}

The hourly variation of the thermal heat flux transfer in $\mathrm{W} / \mathrm{m}^{2}$, for both the single-layered glass window and the proposed system of using a glass window with frame-type VIP as an example, is displayed in Figs. 21-a and b for Sapporo and Ishigaki, respectively. Based on these two figures, it is evident that attaching the VIP to the single-layer glass windows of existing buildings reduces the heat loss from the building and the heat gains to the buildings in cold and hot weather conditions, respectively. Further, it is highly 
recommended to apply this idea in cold regions such as Sapporo, as the high temperature difference between the outside ambient temperature and the inside designed conditions can be very high some days, e.g. reaching $30^{\circ} \mathrm{C}$.
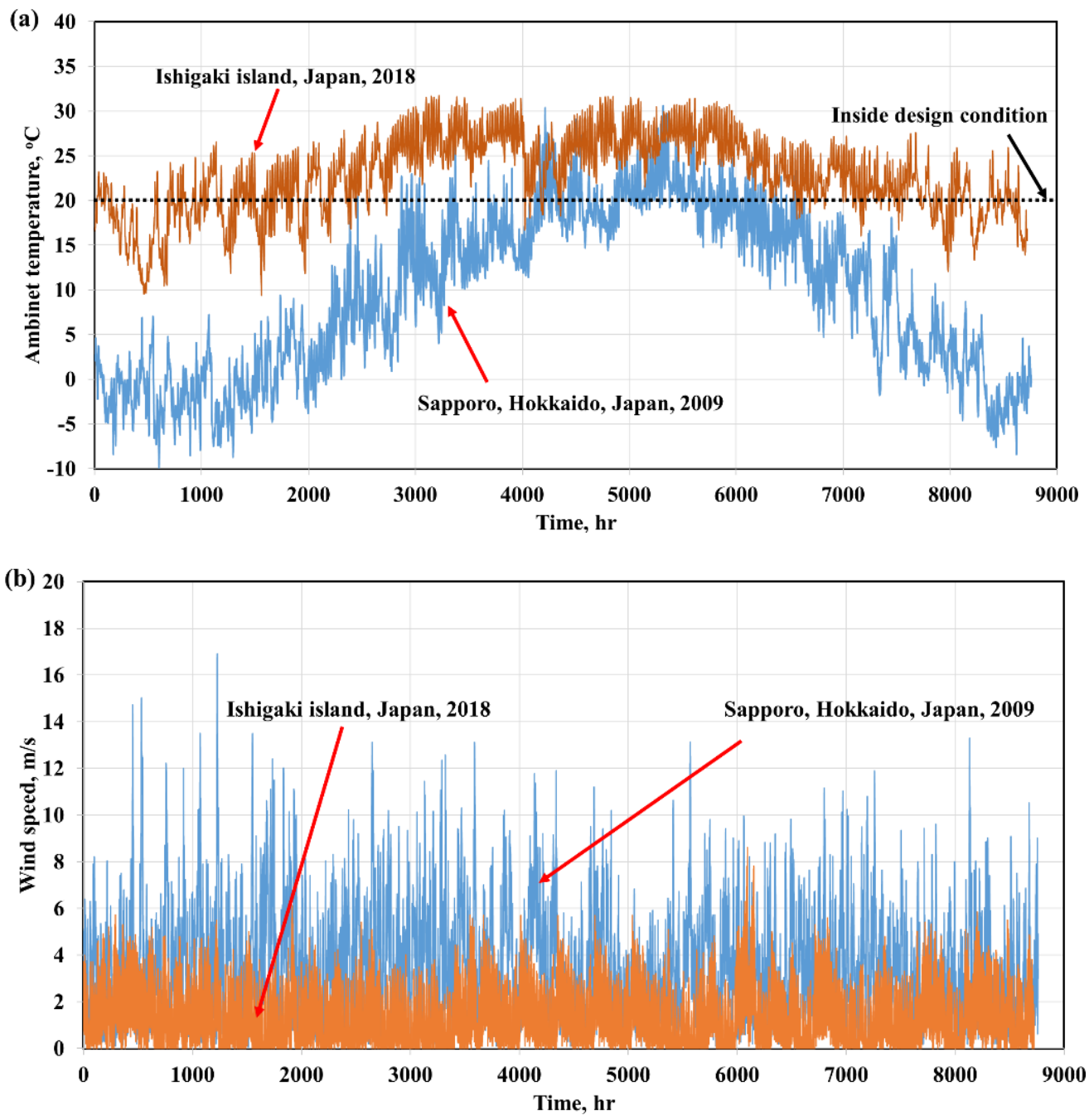

Fig. 20 Hourly variation of (a) ambient temperature and (b) wind speed for Ishigaki and Sapporo cities in Japan.

The total annual thermal energy flux transfer in $\mathrm{kW} . \mathrm{h} / \mathrm{m}^{2}$ is calculated and compared for all of the studied VIPs in Figs. 22-a and b for Sapporo and Ishigaki, respectively. First, the total annual rate heat flux transfer in $\mathrm{W} / \mathrm{m}^{2}$ is divided into loss and gain. The hourly integrations of both rates are displayed in the figure. For the Sapporo region, it is evident that the total annual heat flux loss is much higher than the heat gain in this region, owing to the cold weather. In addition, using a frame VIP attached to $3 \mathrm{~mm}$ glass window reduces the heat loss from the buildings by up to $69.5 \%$. In contrast, for Ishigaki region, the heat gain from the window is much higher than the heat loss, and a $65.1 \%$ reduction in the annual heat gain is accomplished by attaching the frame-type VIP to the existing $3 \mathrm{~mm}$ glass windows. 

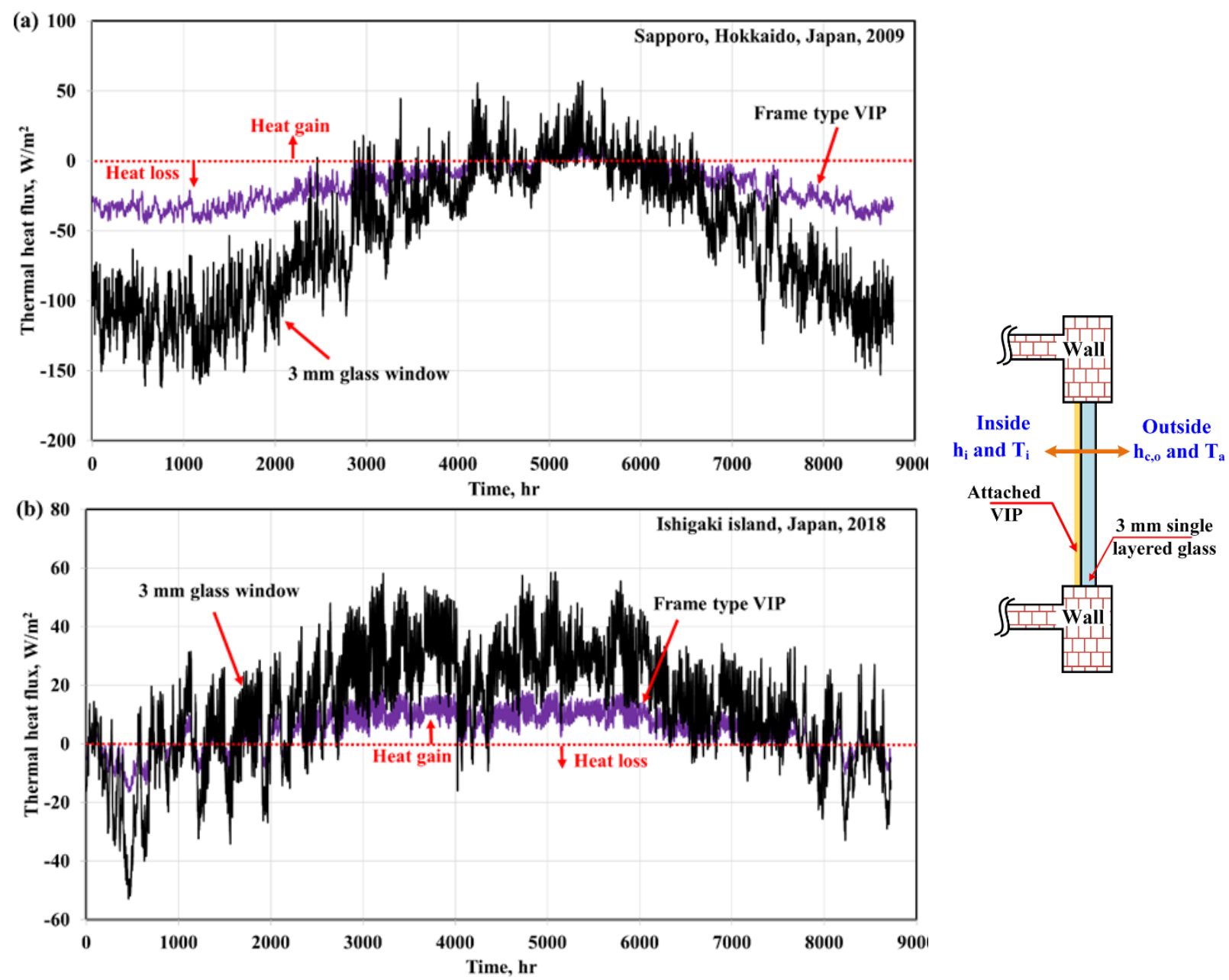

Fig. 21 Hourly variation of the thermal heat flux transfer in $\mathrm{W} / \mathrm{m}^{2}$ for (a) Sapporo and (b) Ishigaki in the case of using single-layered glass window and the frame-type VIP attached to the glass window as an example. The VIP with the glass window is displayed at the right of the figure.
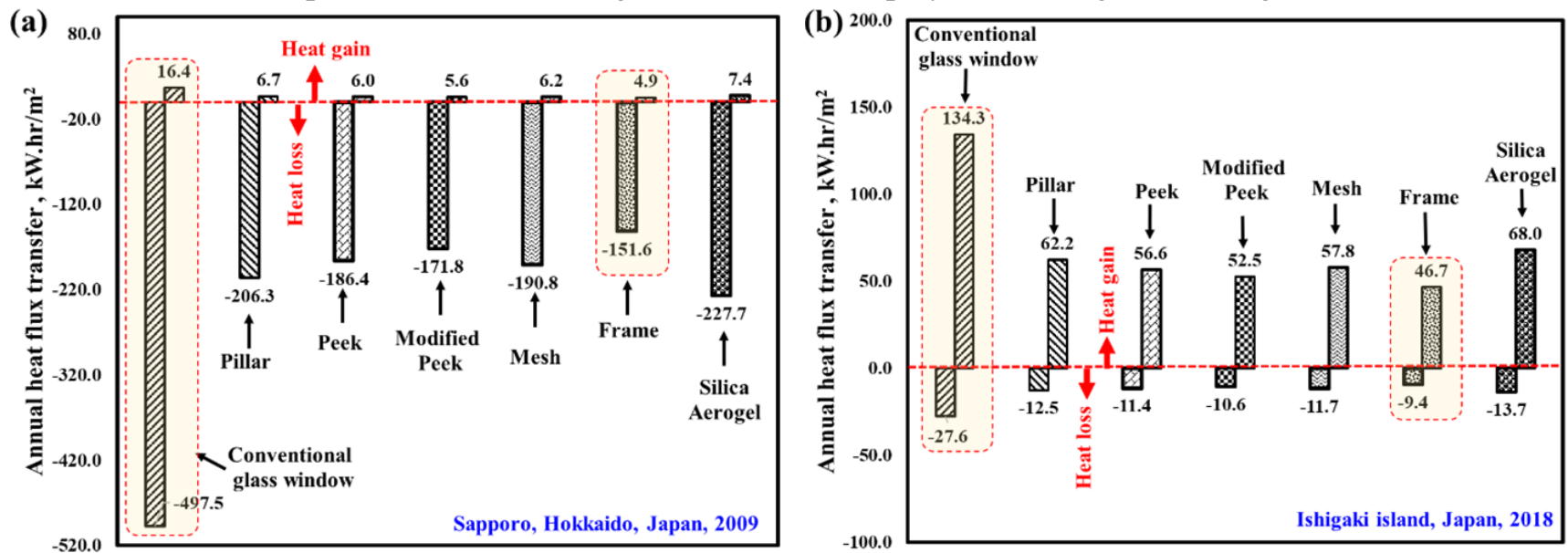

Fig. 22 Variation of the total annual heat flux transfer in a unit of $\mathrm{kW} \cdot \mathrm{h} / \mathrm{m}^{2}$ for (a) Sapporo and (b) 


\section{Conclusions}

The present study proposes five new and distinct structured-core transparent VIPs. These VIPs are different from the well-known conventional VIP, which has a solid core material structure and opaque metallized film barrier envelope. The VIPs herein are proposed so as to accomplish high thermal insulation for the windows of existing buildings. The centre-of-panel thermal conductivity, transparency, and cost are experimentally evaluated. In addition, four trial manufacturing methods for these VIPs are proposed and compared. Further, a 3D thermal model is developed and numerically solved, and is validated via experiments. Based on the results, it is determined that the frame and mesh-type spacers accomplished the lowest centre-of-panel thermal conductivities of $6.5 \times 10^{-3}$ and $6.8 \times 10^{-3} \mathrm{~W} / \mathrm{m} . \mathrm{K}$ at a vacuum pressure of 1 Pa with thicknesses of $3 \mathrm{~mm}$ and $2 \mathrm{~mm}$, respectively. Further, it is concluded that the use of a getter adsorbent material during the manufacturing process of the VIPs keeps the inside pressure stable for a longer period of time. Furthermore, at ASTM boundary conditions, the predicted U-values for the mesh spacers and conventional silica aerogel spacers were $1.14 \mathrm{~W} / \mathrm{m}^{2} . \mathrm{K}$ and $1.84 \mathrm{~W} / \mathrm{m}^{2} . \mathrm{K}$, respectively. However, the use of mesh spacers is economically competitive with silica aerogels.

\section{Acknowledgements}

This work is financially supported by the Grants-in-Aid for Scientific Research of the JSPS (Research representative: Takao Katsura). The authors also thank Mr. Masahiro Aihara, Ms. Ririko Noda in Graduate School of Hokkaido University, Mr Yuji Mori in Faculty of Engineering, Hokkaido University, Hokkaido Electric Power Co. Inc., Mitsubishi Chemical Corporation, Teijin Frontier Co., Ltd., ULVAC Inc., and Miyoshi Vacuum Packing for their assistance in the VIP test production.

\section{Nomenclature}

A vacuum insulation panel front area $\left[\mathrm{m}^{2}\right]$

$C \quad$ thermal conductance $\left[\mathrm{W} /\left(\mathrm{m}^{2} . \mathrm{K}\right)\right]$

$C_{b} \quad$ black body radiation constant factor $\left[\mathrm{W} /\left(\mathrm{m}^{2} . \mathrm{K}^{4}\right)\right]$

$E \quad$ emissive power density $\left[\mathrm{W} / \mathrm{m}^{2}\right]$

$F \quad$ radiation view factor [unitless]

$h_{c, i} \quad$ convective heat transfer coefficient inside the building $\left[\mathrm{W} /\left(\mathrm{m}^{2} . \mathrm{K}\right)\right]$

$h_{c, o} \quad$ convective heat transfer coefficient on the outer glass surface $\left[\mathrm{W} /\left(\mathrm{m}^{2} . \mathrm{K}\right)\right]$

$J \quad$ radiosity $\left[\mathrm{W} / \mathrm{m}^{2}\right]$

$k \quad$ thermal conductivity [W/(m.K)]

$l_{v} \quad$ VIP thickness [m]

$P \quad$ pressure $\left[\mathrm{N} / \mathrm{m}^{2}\right]$

$q \quad$ heat flux either on the hot or the cold side of the VIP $\left[\mathrm{W} / \mathrm{m}^{2}\right]$

$T$ temperature $\left[{ }^{\circ} \mathrm{C}\right]$

$U_{\infty} \quad$ wind speed $[\mathrm{m} / \mathrm{s}]$

\section{Greek symbols}

$\Delta \quad$ difference 
$914 \quad \varepsilon \quad$ emissivity [unitless]

$915 \lambda_{o} \quad$ thermal conductivity of the air at the room temperature and pressure [W/(m.K)]

$916 \lambda_{v} \quad$ thermal conductivity of the vacuum space [W/(m.K)]

$917 \sigma \quad$ Stephan Boltzmann constant $5.67 \times 10^{-8}\left[\mathrm{~W} /\left(\mathrm{m}^{2} . \mathrm{K}^{4}\right)\right]$

\section{Subscripts}

919 a ambient

920 avg average

$921 \quad c \quad$ cold side of the VIP

922 eff effective

$923 g$ glass

$924 h \quad h \quad$ hot side of the VIP

$925 \quad h-c \quad$ between the hot and the cold side of the VIP

$926 \quad i \quad$ inside the building

927 in entering the surface

928 out exiting from the surface

$929 \quad v \quad$ VIP

930

931

\section{References}

932

933

934

935

936

937

938

939

940

941

942

943

944

945

946

947

ANSYS FLUENT Theory Guide, 2011.

Araki, K., Kamoto, D., Matsuoka, S. ichi, 2009. Optimization about multilayer laminated film and getter device materials of vacuum insulation panel for using at high temperature. J. Mater. Process. Technol. 209, 271-282. https://doi.org/10.1016/j.jmatprotec.2008.01.054

Arya, Farid, Moss, R., Hyde, T., Shire, S., Henshall, P., Eames, P., 2018. Vacuum enclosures for solar thermal panels Part 1: Fabrication and hot-box testing. Sol. Energy 174, 1212-1223. https://doi.org/https://doi.org/10.1016/j.solener.2018.10.064

Arya, F., Moss, R., Hyde, T., Shire, S., Henshall, P., Eames, P., 2018. Vacuum enclosures for solar thermal panels Part 2: Fabrication and hot-box testing. Sol. Energy 1212-1223. https://doi.org/10.1016/j.solener.2018.10.064

Baetens, R., Jelle, B.P., Thue, J.V., Tenpierik, M.J., Grynning, S., Uvsløkk, S., Gustavsen, A., 2010. Vacuum insulation panels for building applications: A review and beyond. Energy Build. 42, 147-172. https://doi.org/10.1016/j.enbuild.2009.09.005

Boafo, F.E., Kim, J.-H., Kim, J.-T., 2019. Numerical study of slim curtain wall spandrel with integrated vacuum insulation panel: Concept, performance evaluation and challenges. Energy Build. 183, 139150. https://doi.org/https://doi.org/10.1016/j.enbuild.2018.10.036

Bouquerel, M., Duforestel, T., Baillis, D., Rusaouen, G., 2012a. Heat transfer modeling in vacuum insulation panels containing nanoporous silicas - A review. Energy Build. 54, 320-336. https://doi.org/10.1016/j.enbuild.2012.07.034

Bouquerel, M., Duforestel, T., Baillis, D., Rusaouen, G., 2012b. Mass transfer modeling in gas barrier 
envelopes for vacuum insulation panels: A review. Energy Build. 55, 903-920. https://doi.org/10.1016/j.enbuild.2012.09.004

Buratti, C., Moretti, E., Zinzi, M., 2017. High Energy-Efficient Windows with Silica Aerogel for Building Refurbishment: Experimental Characterization and Preliminary Simulations in Different Climate Conditions. Build. . https://doi.org/10.3390/buildings7010008

Choi, B., Yeo, I., Lee, J., Kang, W.K., Song, T.H., 2016. Pillar-supported vacuum insulation panel with multi-layered filler material. Int. J. Heat Mass Transf. 102, 902-910. https://doi.org/10.1016/j.ijheatmasstransfer.2016.06.032

Collins, R.E., Simko, T.M., 1998. Current status of the science and technology of vacuum glazing. Sol. Energy 62, 189-213. https://doi.org/10.1016/S0038-092X(98)00007-3

Fang, Y., Eames, P.C., Norton, B., Hyde, T.J., 2006. Experimental validation of a numerical model for heat transfer in vacuum glazing. Sol. 564-577. https://doi.org/https://doi.org/10.1016/j.solener.2005.04.002

Fang, Y., Eames, P.C., Norton, B., Hyde, T.J., Zhao, J., Wang, J., Huang, Y., 2007. Low emittance coatings and the thermal performance of vacuum glazing. Sol. Energy 81, 8-12. https://doi.org/10.1016/j.solener.2006.06.011

Fang, Y., Hyde, T., Hewitt, N., Eames, P.C., Norton, B., 2009. Comparison of vacuum glazing thermal performance predicted using two- and three-dimensional models and their experimental validation. Sol. Energy $\quad$ Mater. Sol. Cells https://doi.org/https://doi.org/10.1016/j.solmat.2009.03.025

Fang, Y., Hyde, T.J., Hewitt, N., 2010. Predicted thermal performance of triple vacuum glazing. Sol. Energy 84, 2132-2139. https://doi.org/https://doi.org/10.1016/j.solener.2010.09.002

Fantucci, S., Garbaccio, S., Lorenzati, A., Perino, M., 2019. Thermo-economic analysis of building energy retrofits using VIP - Vacuum Insulation Panels. Energy Build. 196, 269-279. https://doi.org/https://doi.org/10.1016/j.enbuild.2019.05.019

Fricke, J., Heinemann, U., Ebert, H.P., 2008. Vacuum insulation panels-From research to market. Vacuum 82, 680-690. https://doi.org/10.1016/j.vacuum.2007.10.014

Incropera, F.P., DeWitt, D.P., Bergman, T.L., Lavine, A.S., 2007. Fundamentals of Heat and Mass Transfer, Water, Dekker Mechanical Engineering. John Wiley \& Sons. https://doi.org/10.1016/j.applthermaleng.2011.03.022

Jang, C., Kim, J., Song, T.H., 2011. Combined heat transfer of radiation and conduction in stacked radiation shields for vacuum insulation panels. Energy Build. 43, 3343-3352. https://doi.org/10.1016/j.enbuild.2011.08.036

Johansson, P., Adl-Zarrabi, B., Hagentoft, C.E., 2012. Using transient plane source sensor for determination of thermal properties of vacuum insulation panels. Front. Archit. Res. 1, 334-340. https://doi.org/10.1016/j.foar.2012.09.004

Jung, H., Yeo, I., Song, T.H., 2014. Al-foil-bonded enveloping and double enveloping for application to vacuum insulation panels. Energy Build. 84, 595-606. https://doi.org/10.1016/j.enbuild.2014.08.045

Katsura, T., Yang, Z., Aihara, M., Nakamura, M., Nagano, K., 2018. Development of Slim and Translucent 
1012

1013

1014

1015

1016

1017

1018

1019

1020

1021

1022

1023

1024

1025

1026

1027

1028

1029

Kim, J., Jang, C., Song, T.H., 2012a. Combined heat transfer in multi-layered radiation shields for vacuum insulation panels: Theoretical/numerical analyses and experiment. Appl. Energy 94, 295-302. https://doi.org/10.1016/j.apenergy.2012.01.072

Kim, J., Lee, J.H., Song, T.H., 2012b. Vacuum insulation properties of phenolic foam. Int. J. Heat Mass Transf. 55, 5343-5349. https://doi.org/10.1016/j.ijheatmasstransfer.2012.05.051

Kim, J., Song, T.H., 2013. Vacuum insulation properties of glass wool and opacified fumed silica under variable pressing load and vacuum level. Int. J. Heat Mass Transf. 64, 783-791. https://doi.org/10.1016/j.ijheatmasstransfer.2013.05.012

Kwon, J.S., Jang, C.H., Jung, H., Song, T.H., 2010. Vacuum maintenance in vacuum insulation panels exemplified with a staggered beam VIP. Energy Build. 42, 590-597. https://doi.org/10.1016/j.enbuild.2009.10.029

Kwon, J.S., Jang, C.H., Jung, H., Song, T.H., 2009. Effective thermal conductivity of various filling materials for vacuum insulation panels. Int. J. Heat Mass Transf. 52, 5525-5532. https://doi.org/10.1016/j.ijheatmasstransfer.2009.06.029

Kwon, J.S., Jung, H., Yeo, I.S., Song, T.H., 2011. Outgassing characteristics of a polycarbonate core material for vacuum insulation panels. Vacuum 85, 839-846. https://doi.org/10.1016/j.vacuum.2010.12.009

Lee, J., Song, T.-H., 2019. Conduction/radiation combined heat transfer with contact resistance for application to vacuum insulation. Int. J. Heat Mass Transf. 129, 380-388. https://doi.org/https://doi.org/10.1016/j.ijheatmasstransfer.2018.09.085

Liang, Y., Wu, H., Huang, G., Yang, J., Wang, H., 2017. Thermal performance and service life of vacuum insulation panels with aerogel composite cores. Energy Build. 154, 606-617. https://doi.org/10.1016/j.enbuild.2017.08.085

Lorenzati, A., Fantucci, S., Capozzoli, A., Perino, M., 2016. Experimental and numerical investigation of thermal bridging effects of jointed Vacuum Insulation Panels. Energy Build. 111, 164-175. https://doi.org/10.1016/j.enbuild.2015.11.026

Ma, H., Zheng, X., Luo, X., Yi, Y., Yang, F., 2018. Simulation and analysis of mechanical properties of silica aerogels: From rationalization to prediction. Materials (Basel). 11, 1-12. https://doi.org/10.3390/ma11020214

Memon, S., Fang, Y., Eames, P.C., 2019a. The influence of low-temperature surface induction on evacuation, pump-out hole sealing and thermal performance of composite edge-sealed vacuum $\begin{array}{lllll}\text { insulated } \quad \text { glazing. } & \text { Renew. } & \text { Energy }\end{array}$ https://doi.org/https://doi.org/10.1016/j.renene.2018.12.025

Memon, S., Fang, Y., Eames, P.C., 2019b. The influence of low-temperature surface induction on evacuation, pump-out hole sealing and thermal performance of composite edge-sealed vacuum insulated glazing. Renew. Energy 135, 450-464. https://doi.org/10.1016/j.renene.2018.12.025

Palyvos, J.A., 2008. A survey of wind convection coefficient correlations for building envelope energy systems' modeling.

Appl.

Therm.

Eng.

28,

801-808. 

https://doi.org/10.1016/j.applthermaleng.2007.12.005

Paneri, A., Wong, I.L., Burek, S., 2019. Transparent insulation materials: An overview on past, present and $\begin{array}{lllll}\text { future } & \text { developments. } & \text { Sol. } & \text { Energy } & \text { 184, }\end{array}$ https://doi.org/https://doi.org/10.1016/j.solener.2019.03.091

Spagnol, S., Lartigue, B., Trombe, A., Gibiat, V., 2007. Thermal modeling of two-dimensional periodic fractal patterns, an application to nanoporous media. Europhys. Lett. 78, 46005. https://doi.org/10.1209/0295-5075/78/46005

Thiessen, S., Knabben, F.T., Melo, C., Gonçalves, J.M., 2018. A study on the effectiveness of applying vacuum insulation panels in domestic refrigerators. Int. J. Refrig. 96, 10-16. https://doi.org/https://doi.org/10.1016/j.ijrefrig.2018.09.006

Woignier, T., Primera, J., Alaoui, A., Etienne, P., Despestis, F., Calas-Etienne, S., 2015. Mechanical Properties and Brittle Behavior of Silica Aerogels. Gels . https://doi.org/10.3390/gels1020256

Yang, Z., Katsura, T., Aihara, M., Nakamura, M., Nagano, K., 2018. Investigation into window insulation retrofitting of existing buildings using thin and translucent frame-structure vacuum insulation panels. Energies 11. https://doi.org/10.3390/en11020298

Yang, Z., Katsura, T., Aihara, M., Nakamura, M., Nagano, K., 2017. Development of numerical heat transfer and the structural model to design slim and translucent vacuum layer type insulation panels to retrofitting insulation in existing buildings. Energies 10. https://doi.org/10.3390/en10122108 